Aroueología Y SociedAd

№ 24, 2012: 371-392

ISSN: 0254-8062

RECIBIDO: MARZO DE 2012

ACEPTADO: AGOSTO DE 2012

\title{
DESCUBRIMIENTOS ARQUEOLÓGICOS EN HUACA HUANTILLE, VALLE BAJO DEL RÍMAC, DURANTE EL PERIODO INTERMEDIO TARDIIO
}

\author{
MARCO GUILLÉN HUGO \\ Director del Proyecto Aroueológico Huaca Huantille \\ marcohugo00006@yahoo.es
}

\section{RESUMEN}

El monumento Huaca Huantille, se caracteriza por su construcción en base a muros de tapia, que fueron utilizados a manera de grandes terrazas para su fachada, lo cual le dio una morfología de una gran pirámide trunca que alcanzó una altura de $16 \mathrm{~m}$, así como la utilización de muros gruesos a doble cara para sus recintos interiores, ubicados en la parte alta de edificio.; la mayoría pintados de color blanco. Los recintos son de planta ortogonal, y con una seña muy característica que es el elemento arquitectónico de banqueta o sobre piso en L en los espacios de uso ceremonial. Las habitaciones se rellenaban para luego construir sobre estos, con el objetivo de ganar volumen, hasta obtener la dimensión final.

Palabras Clave: Periodo Intermedio Tardío, Ychsma, Lima, Rímac, Magdalena, Huantille.

\section{Abstract}

The monument is known for its construction on the basis of mud walls, which were used as a large terrace for its facade, which gave a morphology of a truncated pyramid that reached a height of $16 \mathrm{~m}$, and the use of double-sided thick walls for their indoor enclosures, located at the top of the building., most painted white. The plant enclosures are orthogonal, and a very characteristic sign is the architectural element of bench or floor spaces L ceremonial use. The rooms were filled and then build on these, in order to gain volume, until the final dimension.

KeYwords: Late Intermediate Period, Ychsma, Lima, Rimac, Magdalena, Huantille.

\section{INTRODUCCIÓN}

En mayo del 2007 se iniciaron las investigaciones en Huaca Huantille, bajo del nombre de "Proyecto de Investigación, Conservación y Puesta en Valor del Sitio Arqueológico Huaca Huantille”, dirigido por el suscrito, gracias a la firma de un convenio de Cooperación Interinstitucional entre la Municipalidad de Magdalena del Mar y el entonces Instituto Nacional de Cultura, a fin de poner en valor el monumento, luego de estar ocupado hasta el año 2006, por más de 50 familias precarias. 
El sitio arqueológico Huaca Huantille está ubicado en el límite noroeste del distrito de Magdalena del Mar, provincia y departamento de Lima, muy cerca al vértice formado por los distritos de Pueblo Libre y San Miguel. Actualmente limita por el Norte con el Jr. Huamanga (antes Marbella), por el Sur con una propiedad privada y la prolongación Echenique, por el Este con la calle Castilla y por el Oeste con una propiedad privada (Fig. 1).

Huaca Huantille se encuentra delimitado oficialmente mediante el plano PP-0080-INC-DREPH/ DA-2004-UG, donde se registra que el sitio arqueológico tiene un área de $11.133,73 \mathrm{~m}^{2}$ y un perímetro de 426,06 m (Fig. 2).

A raíz de los antecedentes históricos y las investigaciones realizadas en el año 2007-2011, se propone que Huaca Huantille, fue el edificio más importante del centro administrativo ceremonial del curacazgo Lima, perteneciente al señorío Ychsma.

Al respecto, Huaca Huantille se caracteriza, en cuanto a su arquitectura, por la utilización funcional de plazas y patios con sobrepisos en forma de L, tratamiento especial de la arquitectura (frisos con diseños geométricos y zoomorfos; muros pintados de blanco y en menor proporción rojo y amarillo), volumetría importante, como la pirámide de hasta $16 \mathrm{~m}$ de alto y con una extensión hasta 3 hectáreas, además presenta una escalinata central como acceso principal, diferente del tradicional patrón de pirámide con rampa (PCR); también, los materiales asociados hallados en los hoyos de ofrenda y evidencias de banquetes y quemas al dejar las distintas fases de ocupación.

En ese sentido, se tiene evidencia que indica que los eventos de demolición y construcción en Huaca Huantille, estaban precedidos por ceremonias en las cuales se ofrendaban vegetales, tales como hojas de pacae, frutos y cáscaras de maní, cañas y tuzas de maíz entre los más significativos, así como productos marinos en menor proporción: cangrejos, moluscos bivalvos y pocos restos ictiológicos.

La cerámica y textiles hallados nos muestran que Huantille tenía algún tipo de acceso a material importado, mediante redes de intercambio, de ahí la presencia significativa de alfarería de estilo Chancay, entre los rellenos constructivos, así como algunos diseños foráneos representados en los textiles.

Todo lo sostenido coloca a Huantille en el escenario de poder discutir los problemas que se han venido planteando para lo Ychsma, desde un sitio local mas allá de Pachacamac, con claro interés por ampliar el conocimiento en las formas arquitectónicas, el material los estilos locales foráneos en la cerámicos y los textiles y una secuencia ocupacional, que por la estratigrafía que se mostrará en este articulo, se presenta como dinámica.

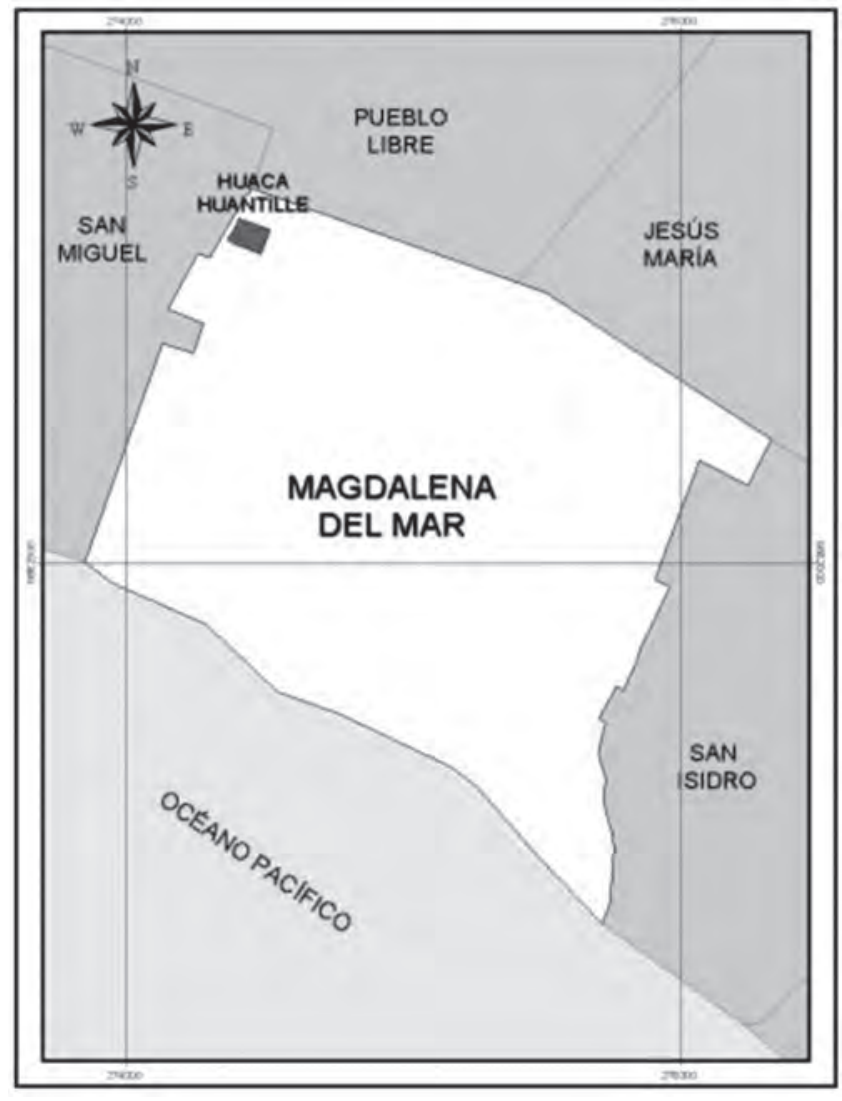

Figura 1: Ubicación de Huaca Huantille. 


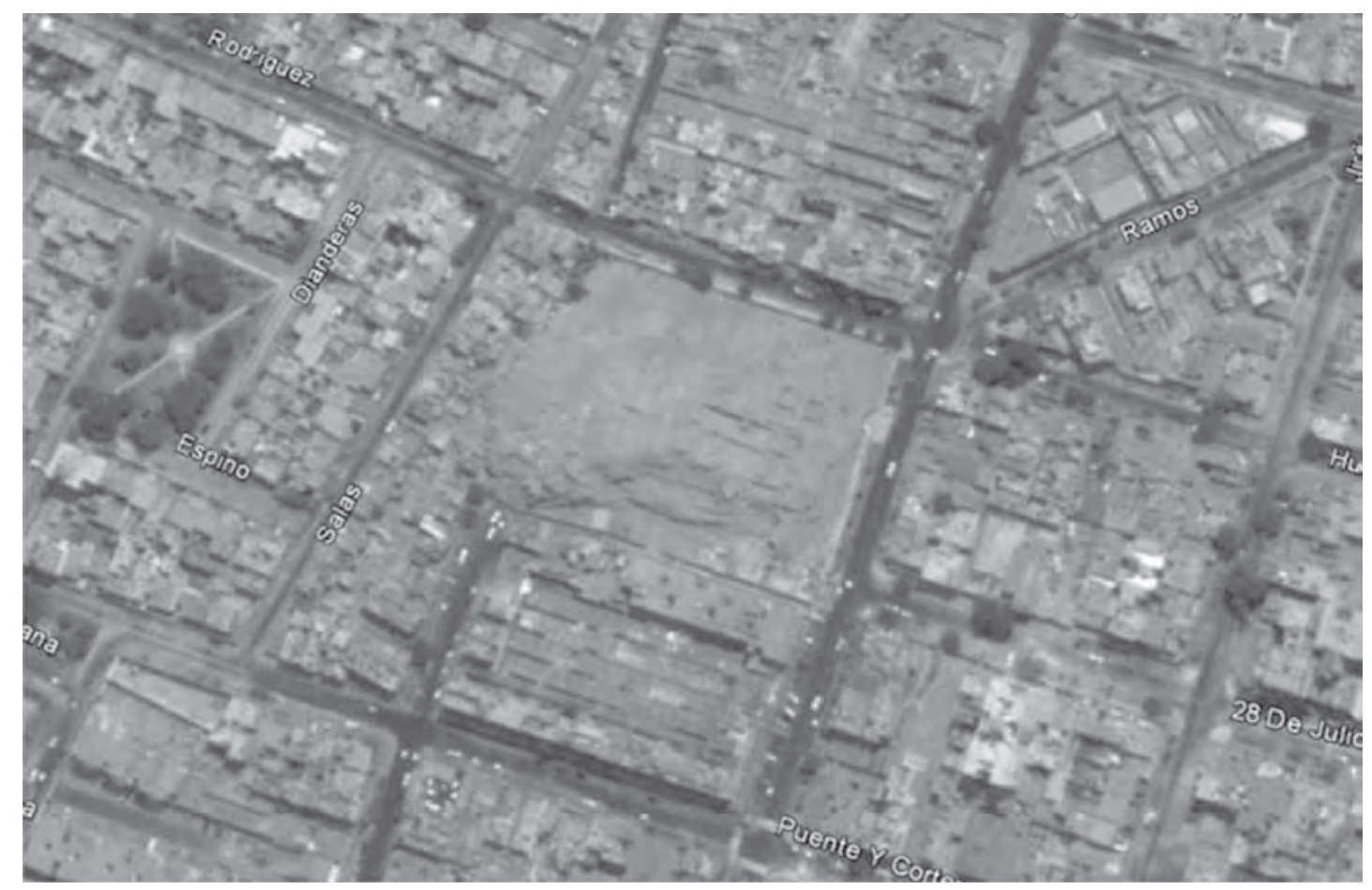

Figura 2: Huaca Huantille en la actualidad. El monumento llegaba por el Sur hasta la Calle Puente y Gómez y hacia el Oeste hasta la Calle Salas.

\section{ANTECEDENTES DE LA INVESTigacióN}

De acuerdo a las fuentes etnohistóricas se señala que en el valle del Rímac a la llegada de los Incas se desarrollaba el denominado señorío Ychsma, que constituía de sies curacazgos en el valle del Rímac, además de uno en el valle de Lurín. Estos curacazgos en el valle del Rímac eran: Ate cuya capital era Puruchuco; Surco con su capital Armatambo; Guatca cuya capital era Limatambo; Lima con su capital Magdalena; Maranga con su capital Maranga; y La Legua con su capital Paredones (Eeckhout 2004; Rostworowski 1978). En ese sentido, el asentamiento prehispánico de Huantille habría formado parte del señorío Ychsma y, a su vez, era parte de uno de los asentamientos principales del curacazgo de Lima, que se extendía por el suroeste hasta el mar y los actuales distritos de Lurigancho, Rímac, San Martín de Porres, Lima, Breña, Pueblo Libre, Magdalena del Mar y San Miguel, con la sede de su gobierno ubicado en las inmediaciones de la Huaca Huantille (Agurto 1984).

Asimismo, a través del Cuaderno de Investigaciones del Archivo Tello podemos conocer la situación de este asentamiento prehispánico, denominado Grupo Arqueológico Huantille durante los años de 1936-1944.

En ese entonces, la importancia del Grupo Arqueológico Huantille era comparada por Tello con El Complejo Arqueológico Mateo Salado "[...] debido a la magnitud de los monumentos allí existentes, el área que ocupan y a la muralla cuadrilateral que limita el espacio. Esta Waka y la vieja Waka Wa[n]tille, situada en San Miguel, se disputan la preeminencia de la ubicación del Templo y oráculo del Rímac" (Tello 1999: 102).

Huaca Huantille era la más importante edificación de un grupo de cinco monumentos que conformaban el grupo Huantille. Los otros cuatro edificios eran de dimensiones menores y se ubicaban alrededor del edificio principal, patrón similar al de Mateo Salado. 


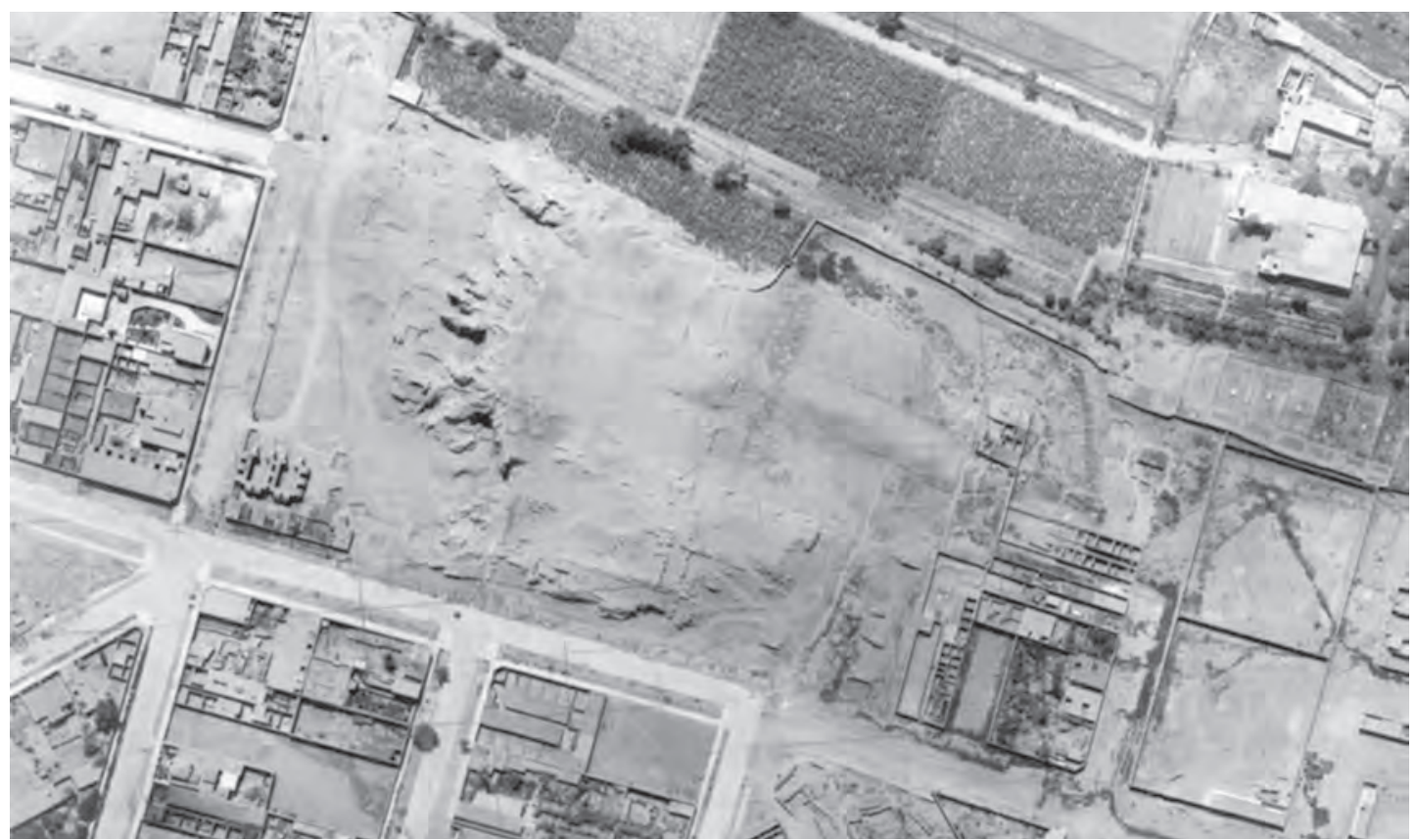

Figura 3: Fotografía aérea de la Zona Arqueológica Huaca Huantille. 1946. Fuente: Servicio Aéreo Nacional.

Lamentablemente -como lo señala Tello (1999)- las disposiciones legales, de aquel entonces (1936), había activado de forma alarmante el derrumbe de los monumentos arqueológicos en el valle del Rímac, "[...] mediante el procedimiento de las inundaciones en masa. Se ha multiplicado, durante los dos últimos años, el numero de fábricas de adobes y ladrillos, desapareciendo monumentos de manera parcial o total, como los de Maka [tampu], en el Fundo Conde de las Torres, los de Limatambo, los de la Waka San Isidro, los de San Miguel o Wantille, y el de Santa Beatriz" (Tello 1999: 100).

A mediados del siglo pasado, entre 1941-1944, Huaca Huantille fue explotada con fines industriales por Víctor Lisandro Proaño y por Tomas Percívale, quienes mediante cortes ilegales al monumento e inundaciones ex profesas, destruían paulatinamente sus estructuras, así como el cementerio con gran cantidad de fardos funerarios ubicado en sus contornos (Fig. 4).

Huaca Huantille, en 1968 fue recortada en el lado sur por la Junta Nacional de Vivienda para construir un mercado, esto llevó a una lenta y progresiva depredación tanto por parte de las autoridades como de los mismos pobladores, a punto tal que en 1972 el propio alcalde de Magdalena del Mar, Alberto Yabar, planteó su demolición con el propósito de construir un centro cívico (Ravines 1984).

En 1987, el entonces alcalde de Magdalena del Mar, Ricardo Flores, pone un cerco perimétrico a zona arqueológica, pero no considera reubicar a los invasores asentados desde la década de los 60.

En ese sentido, el principal problema para la preservación del sitio arqueológico Huaca Huantille, así como

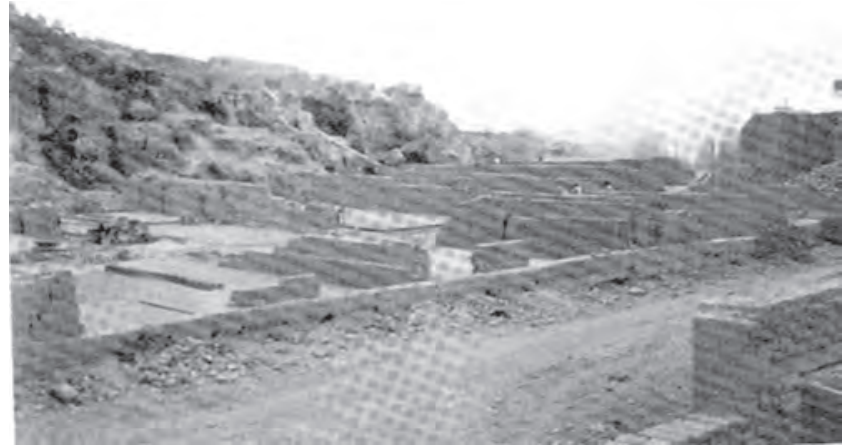

Figura 4: Ladrillera Orbea en Huaca Huantille. Tello 1941. 
de otros sitios arqueológicos de Lima Metropolitana fue la ampliación urbana masiva, y el riesgo que representaba en el recorte ilegal de sitios arqueológicos o destrucción de ellos. Con el crecimiento de Lima hacia zonas antiguamente agrícolas a partir de los 40, comenzó a agudizarse la problemática del estado de conservación de los monumentos, volviéndose susceptibles a la actividad antrópica que se plasmó en Huaca Huantille en acciones vandálicas, grafitis, acumulación de basura, desmonte, proliferación de delincuencia, pernoctación de gente de malvivir, erosión y deterioro de las superficies arqueológicas (Fig. 5).

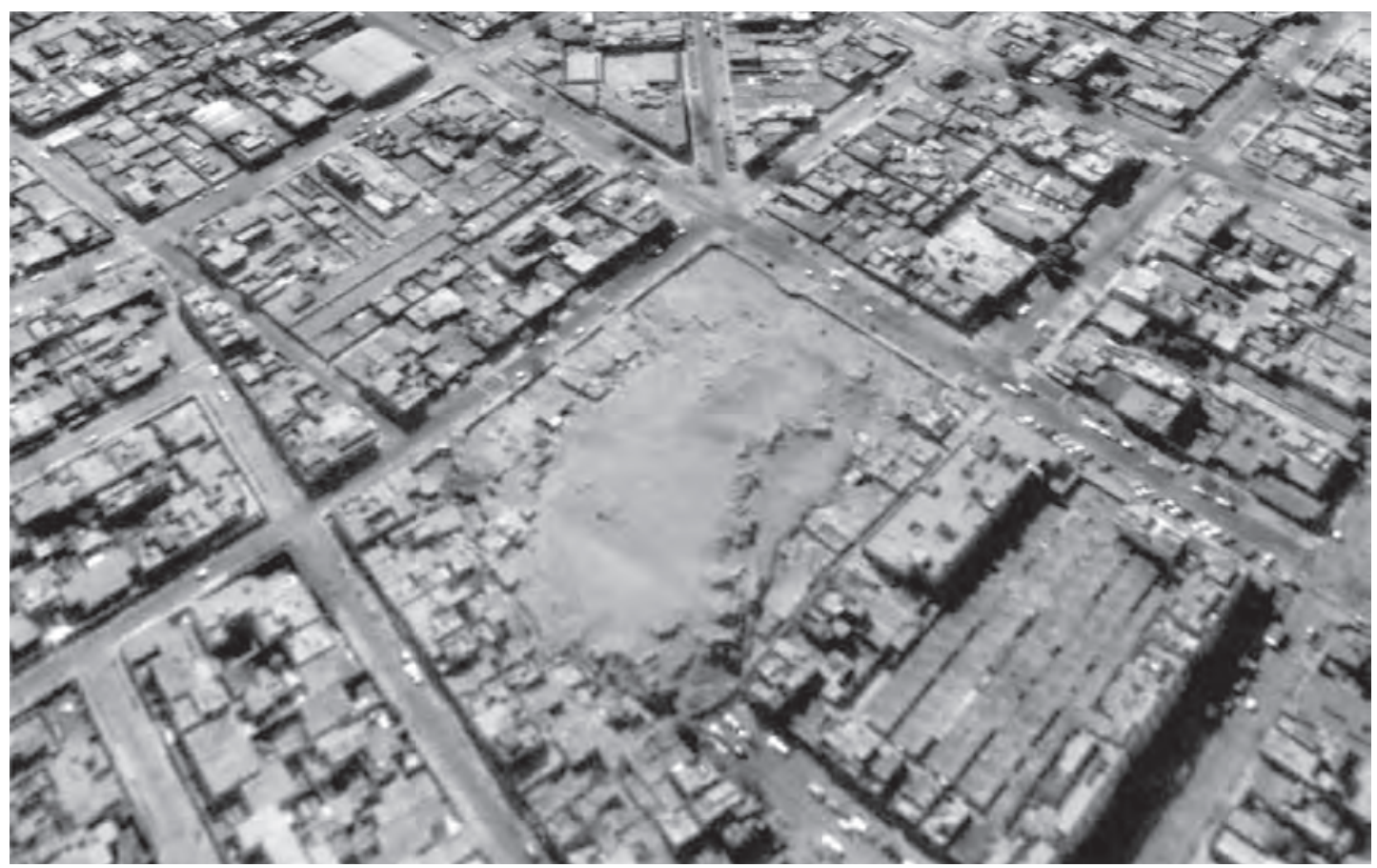

Figura 5: Huaca Huantille invadida. Foto satelital de Google 2006.

\section{Metodología de la eXCAVAción ARQueológicA}

La excavación fue realizada en área con la finalidad de recuperar espacios arquitectónicos así como obtener datos que nos permitan entender las características formales y funcionales de los recintos vislumbrados en superficie, y además, de las últimas fases arquitectónicas del monumento.

Se establecieron cuatro cuadrantes, en relación al norte magnético: Noroeste (NW), Suroeste (SW), Noreste (NE) y Sureste (SE). Al respecto, dentro de los objetivos del proyecto en la temporada 2007, se propuso la excavación del Cuadrante Sureste, para lo cual se dividió el área en unidades de 10 x 10 m, y éstas en cuadrículas de 2 x 2 m.

La excavación arqueológica en área se llevó a cabo tomando el criterio de unidades estratigráficas (Harris 1991) como medio para registrar de manera cabal las formas y características propias de cada uno de los depósitos culturales. La excavación se realizó respetando los contornos y dimensiones naturales, en orden inverso al que fueron depositados. Para la definición de los depósitos culturales se tomó como elementos primordiales la ley de la continuidad original, ley de la horizontalidad original, ley de sucesión estratigráfica y la ley de superposición (Harris 1991: 211).

Debido a las características de las unidades estratigráficas, estas fueron discriminadas de la siguiente manera para su mejor registro e interpretación: 
- Depósitos: Cuerpo tridimensional de materiales separado por superficies horizontales, que posee características internas homogéneas en función a rasgos macroscópicos nítidos que permiten diferenciarlos de otro. Pueden ser de naturaleza antrópica como geológica.

- Cortes: Intrusiones dentro de los depósitos caracterizados por tener menor extensión horizontal que vertical. Dentro de esta categoría están los hoyos de poste, hoyos de huaqueo u otras disturbaciones en los depósitos.

- Estructuras: Cada uno de los elementos arquitectónicos que forman parte de los recintos.

El registro de los depósitos se procesó teniendo en cuenta su naturaleza, dimensiones, características de su superficie, grado de compactación, textura, color, composición y tamaño de las partículas, inclusiones (material cultural) y sus relaciones físicas con otras unidades estratigráficas.

Para el registro de los cortes se tomó en cuenta la forma de la planta, dimensiones, características de las esquinas, de las roturas y de los lados, orientación y relaciones físicas con otras unidades estratigráficas.

En el registro de las estructuras se priorizó el tipo de estructuras: sea muro, piso, rampa, banqueta, entre otras; dimensiones: tipo, tamaño y composición de los materiales de fábrica, forma, técnica constructiva, acabado, orientación y relaciones físicas con otras unidades estratigráficas.

La descripción de las unidades estratigráficas se ha realizado en base a los diarios de campo y al manejo de fichas correspondientes (ficha de registro de depósitos, ficha de registro de corte, ficha de registro de estructuras, ficha de hallazgos especiales y ficha de recinto), además del registro gráfico y fotográfico.

El registro gráfico buscó ubicar las evidencias de manera tridimensional tanto horizontal (largo y ancho) como verticalmente (altura), con relación a los lados de la cuadrícula, registrándolo en un dibujo de planta por lo general en escala 1:20. Asimismo, se llevaron a cabo dibujos de perfiles y cortes en escala 1:20. Además del registro gráfico se llevó de manera paralela el registro fotográfico de las diferentes unidades estratigráficas y de los elementos de importancia mediante cámara digital.

\section{LA ARQUITECTURA Y LA DISTRIBUCIÓN DE LOS ESPACIOS EN HUANTILLE: FORMAS Y SECUENCIA}

El monumento se caracteriza por ser una pirámide aterrazada trunca con escalinata central. Su construcción a base de muros de tapia, que fueron utilizados a manera de grandes terrazas para su fachada, lo cual le dio una morfología de una gran pirámide trunca que alcanzó una altura de $16 \mathrm{~m}$, así como la utilización de muros gruesos a doble cara para sus recintos interiores, ubicados en la parte alta de edificio; la mayoría pintados de color blanco, teniéndose evidencia de muros internos pintados de amarillo, así como muros con decoraciones de volutas de color rojo, en recintos que aun no han sido excavados en su integridad.

A la pirámide se accedía a través de una gran escalinata ubicada al norte del mismo (Fig. 6) con una orientación de $20^{\circ} \mathrm{E}$ con respecto al norte, la cual conduce a un gran patio en la cima, donde se realizaban las ceremonias principales.

Los recintos de Huaca Huantille son de planta ortogonal, y con una seña arquitectónica muy característica en aquellos destinados a ser espacios públicos: poseen banquetas o sobre piso de planta en L. (Fig. 7)

Al respecto, debemos decir que se han encontrado 4 recintos con estas características, tres de ellos coexistiendo en el mismo periodo de ocupación (Periodo B, periodo intermedio de ocupación) y uno para el periodo C (periodo de la ultima ocupación que se ha podido registrar); para el Periodo A (primer periodo de ocupación) no se ha identificado dicha característica. 


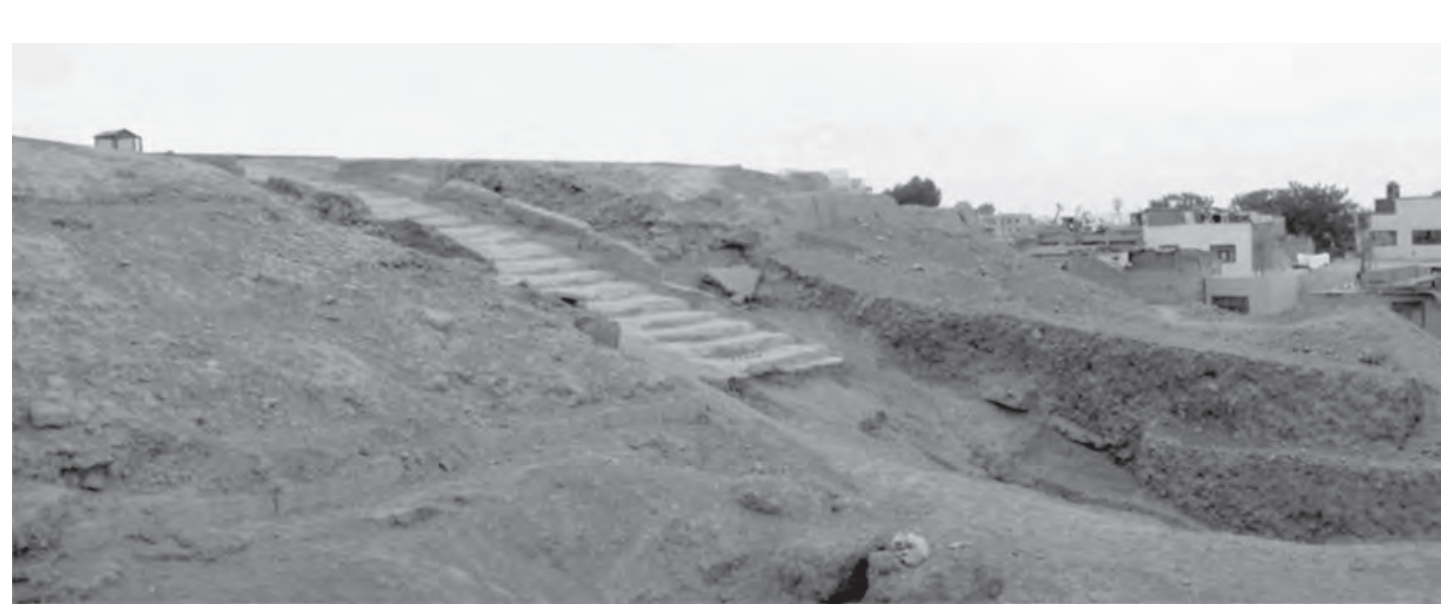

Figura 6. Frontis de la pirámide. Nótese la gran escalinata de acceso hacia la plaza.

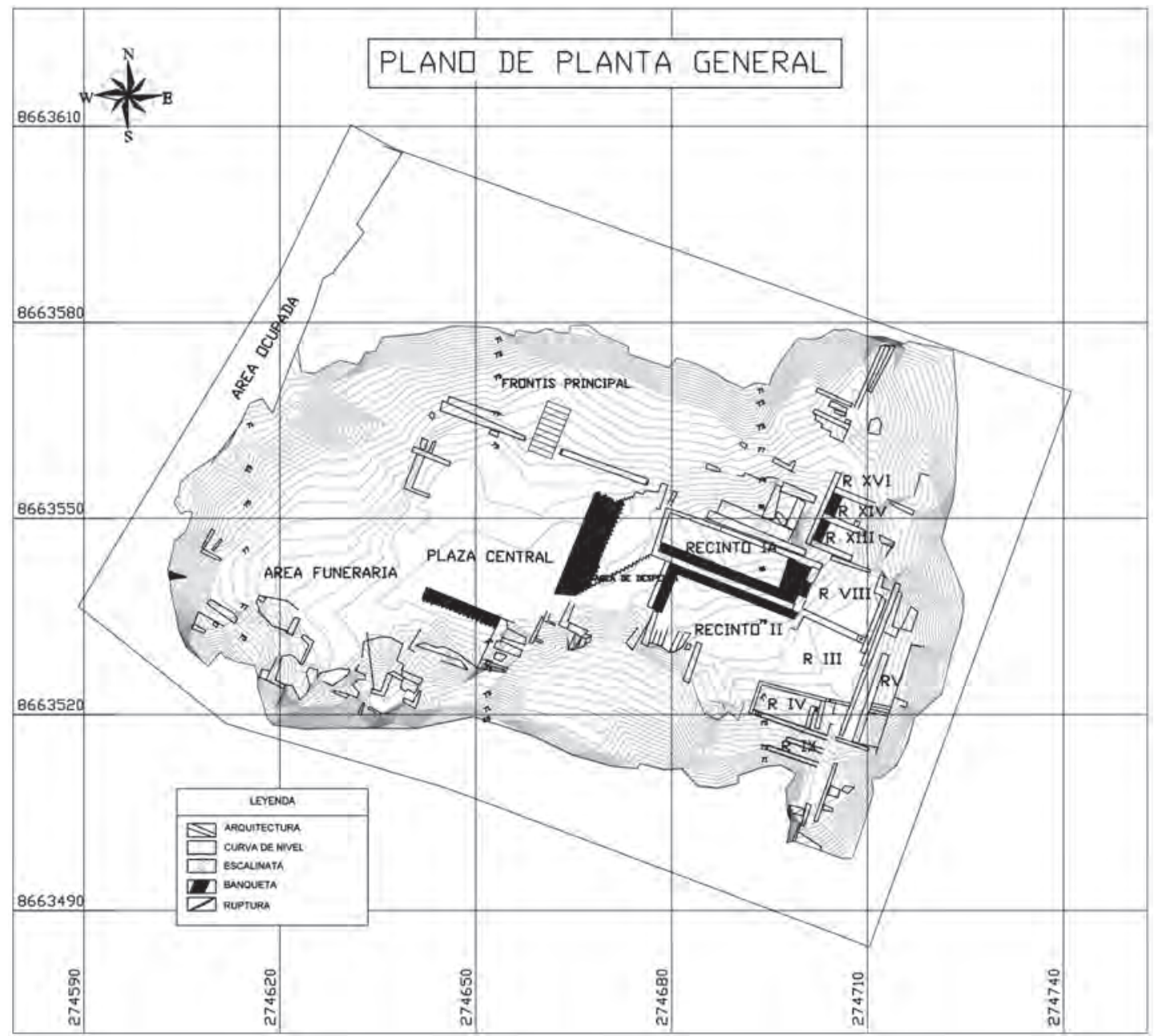

Figura 7. Plano general de Huaca Huantille y sus espacios. 
En el proceso de pasar de un periodo de ocupación antiguo a uno nuevo, las habitaciones se rellenaban para luego construir sobre estas, con el objetivo de ganar volumen, hasta obtener la dimensión final. Siempre creciendo en volumen y altura a fin de demostrar el prestigio y la importancia del grupo social que lo habitaba. De esta forma, hasta el momento se ha logrado identificar hasta 3 periodos de ocupación, en base al análisis arquitectónico, que de arriba hacia abajo son denominados C-A. Todos estos periodos de acuerdo al análisis arquitectónico y material asociado, pertenecientes al Intermedio Tardío.

\section{Distribución del espacio en el Periodo C}

El último periodo de ocupación estuvo dado por el Recinto I y los recintos que existen en la parte más alta del edificio (lo cuales aun no se excavan) ubicados al norte de precitado recinto, con el cual se comunicaban mediante un vano de 1,20 m de ancho (Fig. 8 y Fig. 9). Creemos que este último periodo de ocupación se extendía por todo el edificio, sin embargo debido a la destrucción no ha podido ser conservado quedando evidencia de este hecho, en los rellenos constructivos que existen sobre las plataformas que configuran actualmente los frontis norte y este de la pirámide, así como en la escalinata principal, lo cual nos hace ver que esta última fachada, actualmente destruida, pudo haber estado asociado a estos recintos.

\section{Distribución del espacio en el Periodo B}

Es el periodo mejor conservado del monumento y con más recintos identificados, al respecto comenzaremos con la descripción del espacio más amplio del edificio, constituido por la plaza, con un área de $928 \mathrm{~m}^{2}$.

La plaza o patio central, es un espacio abierto, ubicado al noroeste, al que se accedía desde el exterior mediante una gran escalinata, de la cual se conservan en la actualidad 20 peldaños.

Tiene una dimensión de $32 \mathrm{~m}$ en su lado sur y $29 \mathrm{~m}$ en su lado este, la cual es flanqueada en ambos lados por un sobre piso (piso sobre nivel del piso inmediato inferior) en forma de L con una altura de 0,06 m ( Fig. 10 y Fig. 11).

No se tiene evidencia de la circulación desde la Plaza, hacia el este del edificio, donde se ubica un recinto dedicado al almacenamiento y despensa de líquidos, con evidencia de grandes tinajas; así como hacia el Recinto II (RII), el mismo que cuenta también con el elemento de sobrepiso en forma de L. Es así que estimamos que los accesos habrían estado ubicados hacia el lado sur, los mismos que se encuentran en la actualidad destruidos.

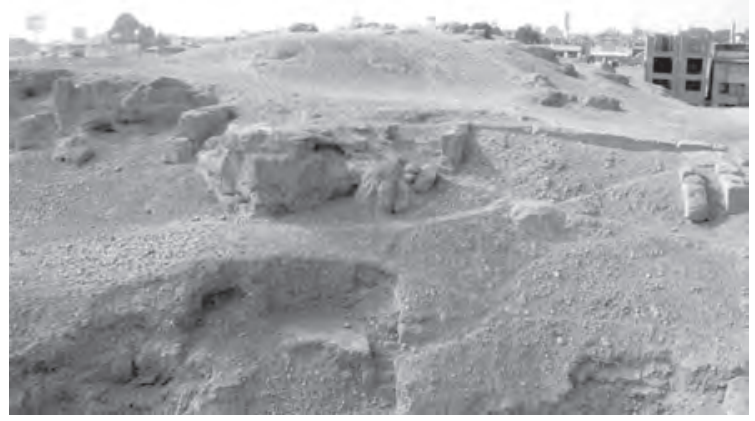

Figura 8. Vista del R I, antes del proceso de excavación. Nótese que el recinto corresponde al promontorio más elevado del edificio.

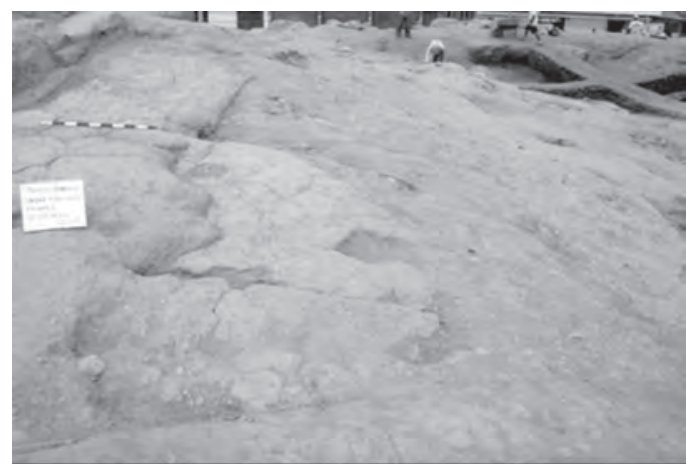

Figura 9: Nótese la disposición del sobre piso en forma de $L$ y el nivel de deterioro del recinto. El recinto fue excavado en su totalidad para llegar hasta el recinto inferior que denominados $R$ IA. 


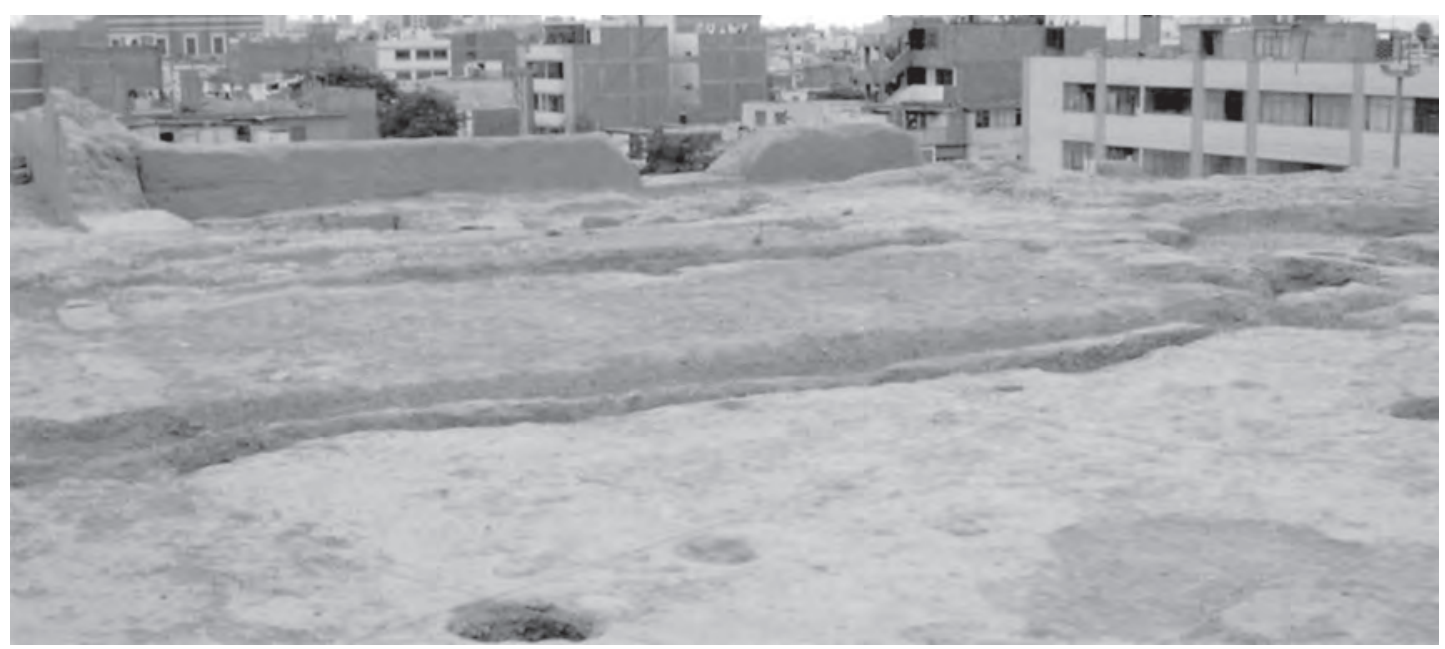

Figura 10. Doble nivel de sobrepiso en la plaza en su lado este.

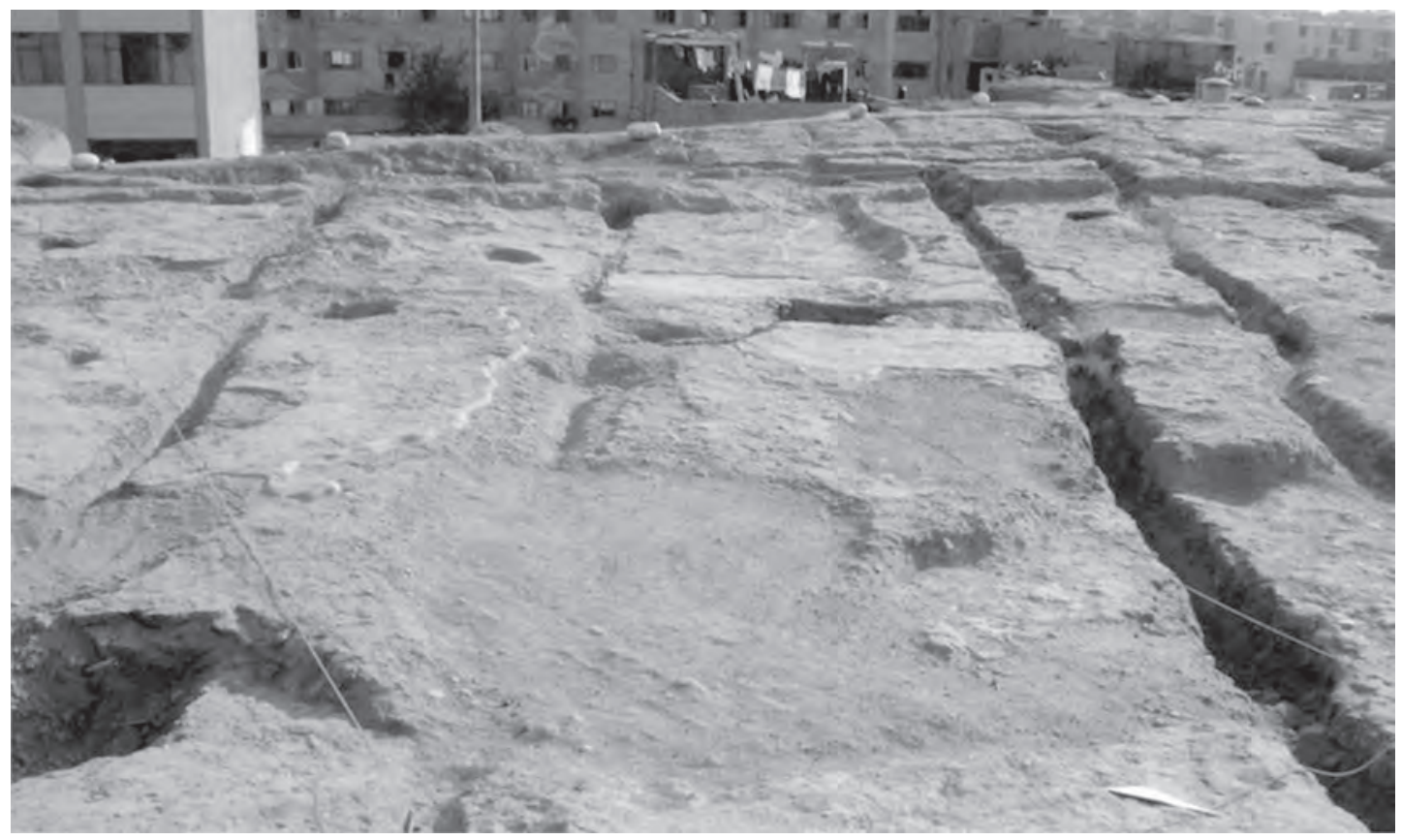

Figura 11. Vista de la plaza en proceso de excavación. Nótese al fondo el sobrepiso del lado sur. La Huaca Huantille fue reutilizada en la época republicana como espacio para corrales de animales, por ello los surcos en el piso.

Siguiendo con la descripción de los recintos con sobrepiso en L, debemos decir que el Recinto II, se encuentra ubicado en la sección Este del edificio y cuenta con una extensión actual de $15 \mathrm{~m}$ en su lado norte y $12 \mathrm{~m}$ en su lado oeste, pudiendo haberse extendido en su lado norte por 6 metros más, hasta llegar a los muros que limitan el frontis Este del monumento y en su lado oeste en una extensión indeterminada (Fig. 12).

El ancho de los sobre pisos en este recinto, varía de acuerdo a su ubicación, es así que en la sección del lado oeste mide 2,62 $\mathrm{m}$ y la sección del lado norte mide 1,52 m de ancho, con una altura en ambos casos de $0,45 \mathrm{~m}$. 


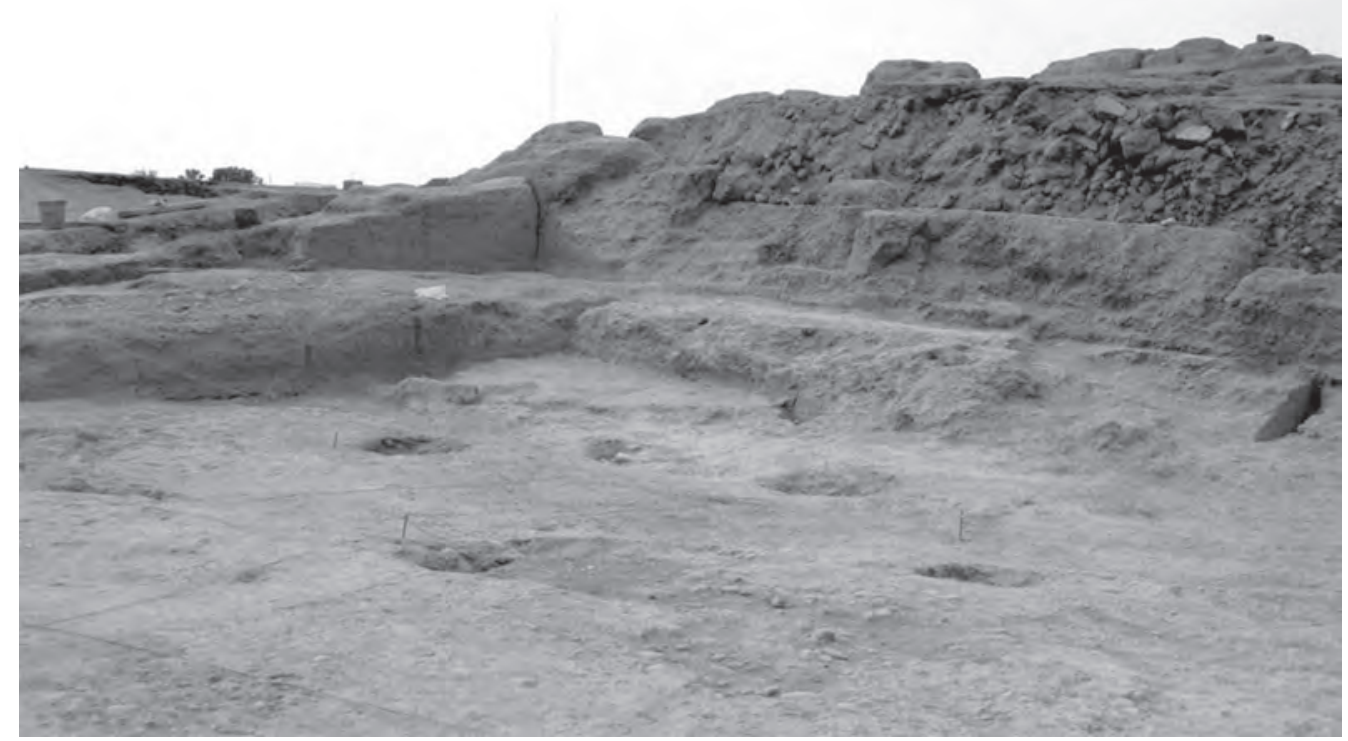

Figura 12. Vista del Recinto II y la disposición de su sobre piso en forma de L. Los hoyos que se observan son de carácter moderno, para el enterramiento de perros en la época que el monumento estaba invadido.

El tercer recinto con sobre piso en forma de L, está consignado por el Recinto R1A,denominado así toda vez que se encuentra exactamente debajo del Recinto I; se encuentra ubicado al norte del recinto RII y al Este del Patio Central; estuvo conectado al RII,a través de un acceso ubicado hacia el Este.

Este recinto fue cubierto en el Periodo C, para la construcción del recinto RI.

El RIA, tiene una extensión de 23,94 m de largo en su lado sur y 5,17 m en su lado este; las secciones de sobrepiso que flanquean ambos lados, tienen un acho de $1,75 \mathrm{~m}$ y 2,35 m respectivamente y una altura de $0,14 \mathrm{~m}$. En la parte alta del muro norte existe la evidencia de lo que pudo ser una hornacina cerca al acceso y otra al extremo oeste (Fig. 13).

El RIA, cuenta con un acceso al lado Este, con un ancho de $2 \mathrm{~m}$, que lo comunicaba con un recinto actualmente destruido en un $70 \%$, por el cual se comunicaba con el RII y con los recintos ubicados al noroeste del edificio: RXIII, RXIV y RXVI (ver Fig.14)

\section{Distribución del espacio en el Periodo A}

El periodo A esta constituido por los Recintos más bajos identificados hasta el momento: III, IV, V, VI, VII, VIII, IX, X.

No se ha identificado para este momento el uso en los recintos del elemento arquitectónico denominado sobre piso en forma de L, característico de los periodos B y C.

Se tratan de recintos rectangulares amplios interconectados entre si mediante vanos de acceso a nivel (R III con R VIII) pasajes (RIII con RIV) y escaleras (RIV con RXI, R IX) (escaleras de conexión de ambientes a desnivel del $\mathrm{R} V$ ).

El cubrimiento de los recintos de este periodo se hace mediante rellenos constructivos caracterizados por tapiales rotos como el usado para $\mathrm{R} \mathrm{IV} \mathrm{y} \mathrm{cantos} \mathrm{rodados} \mathrm{con} \mathrm{tierra,} \mathrm{como} \mathrm{los} \mathrm{usados} \mathrm{para}$ el R VIII.

En el periodo A se ha podido distinguir dos sub periodos, en las cuales se presentan numerosas fases por el cual se amplían y dividen recintos, se sellan accesos y cubren algunos recintos. 


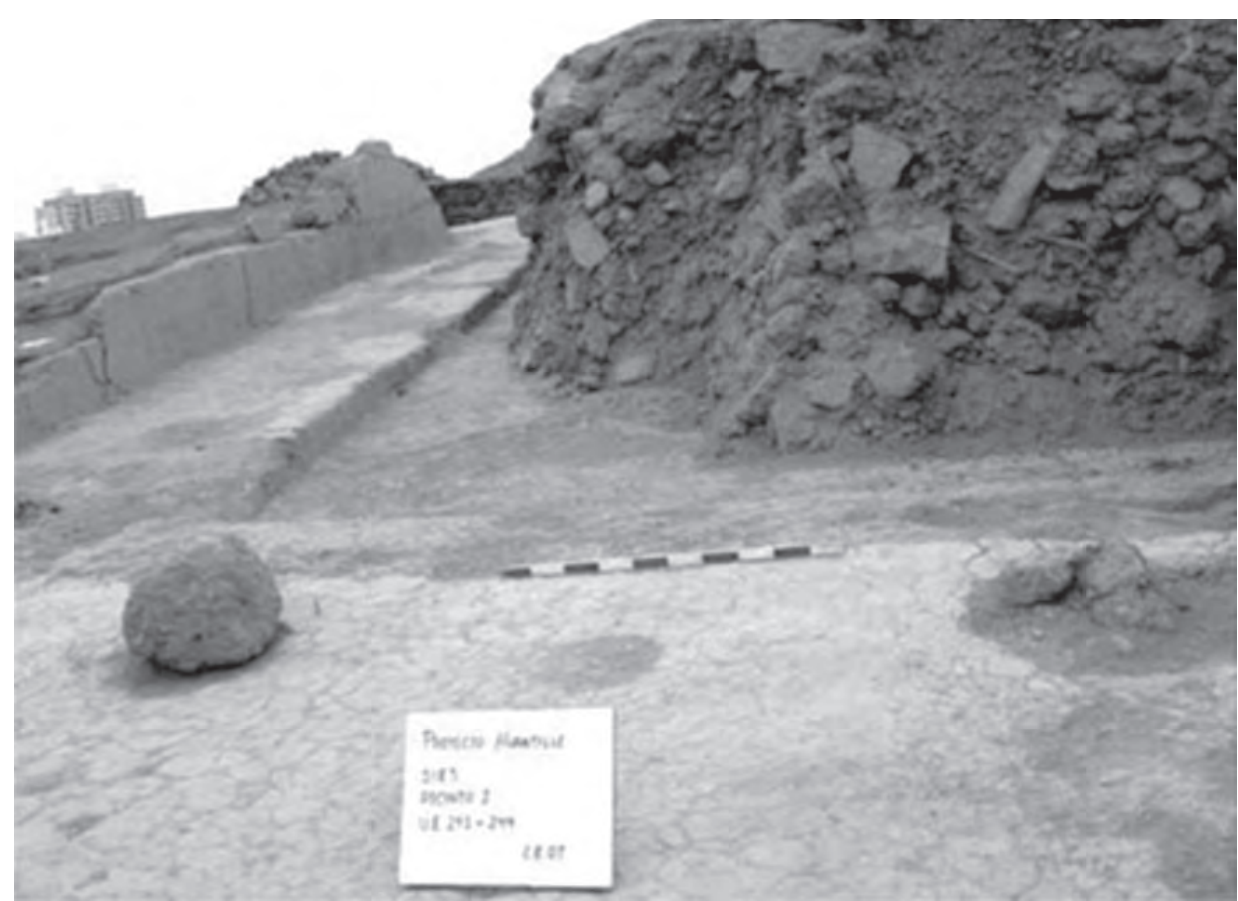

Figura 13. Nótese el sobre piso en forma de L y la disposición de hoyos de poste próximos al acceso ubicado al este.

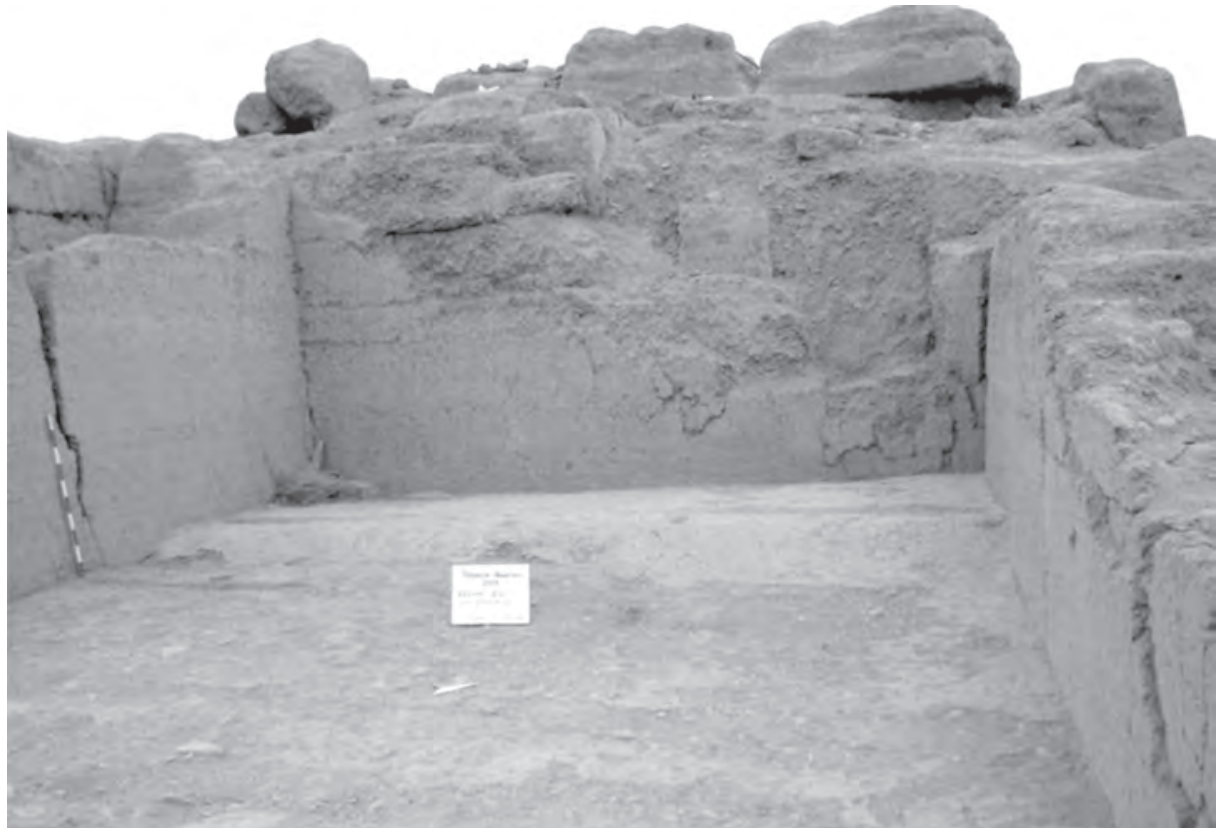

Figura 14. Vista del recinto RXIII, es uno de los tres recintos ubicados al noreste del edificio que cuentan con similares características en cuanto a tamaño y elementos arquitectónicos, como es el caso de la banqueta al fondo del recinto. Estos recintos se disponen a manera de habitaciones contiguas y cuyo acceso debió haber estado hacia el este, actualmente destruido. Los pisos antes de su enterramiento fueron cubiertos por abundante grama salada y otros vegetales. 


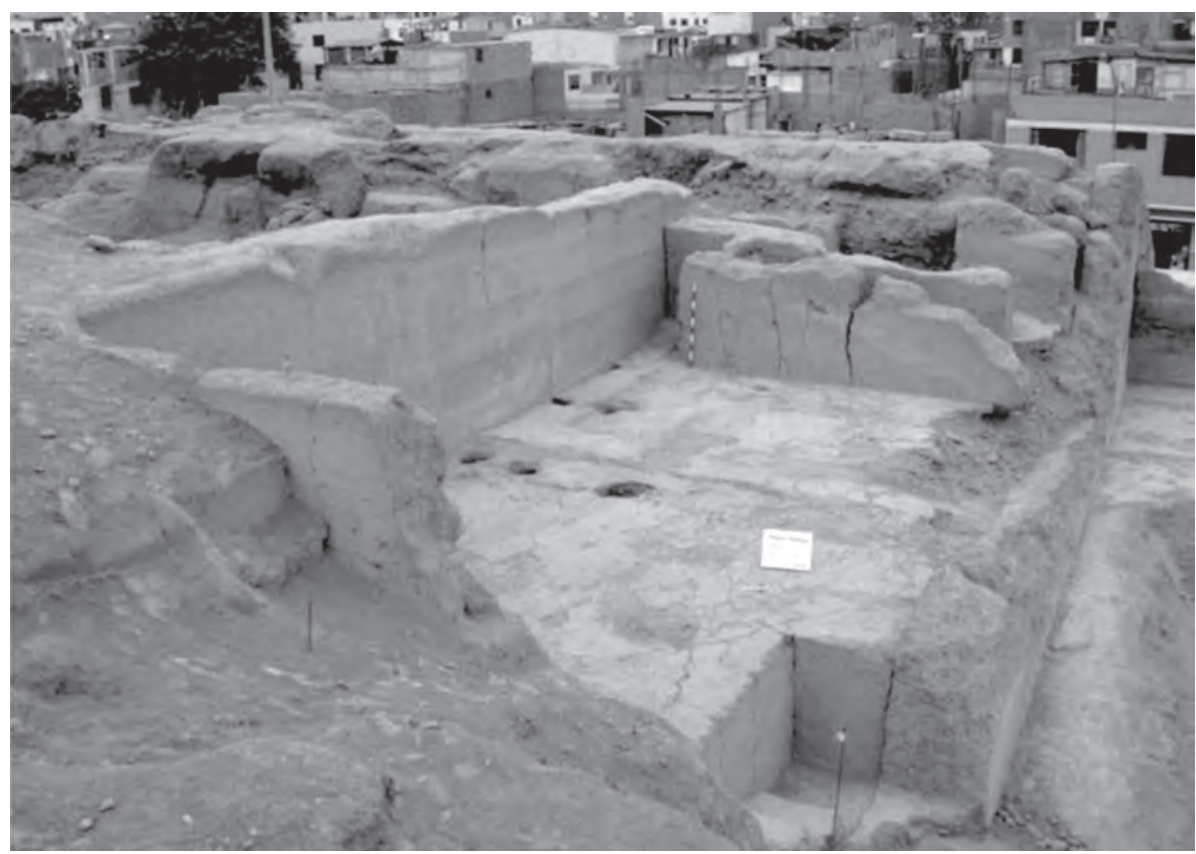

Figura 15. Recinto IV. Nótese que el acceso del recinto en su última fase de ocupación se realizaba a través de una pequeña escalera ubicada en su esquina Sur Oeste y que lo comunicaba con el Recinto XI y R IX. Nótese además el acceso sellado en su esquina Nor Este, que lo comunicaba previamente con RVI, R VII y RIII. La fotografía está tomada desde Oeste al Este.

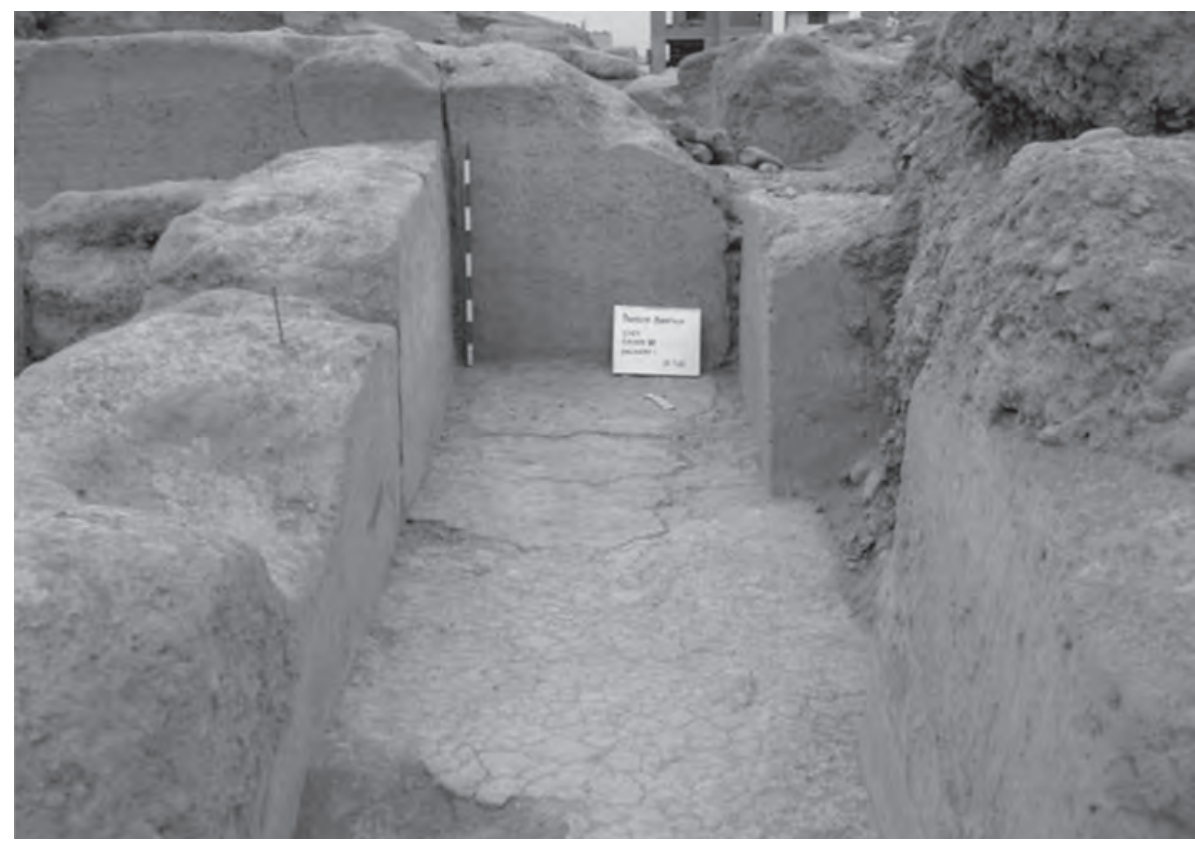

Figura 16. Recinto VII. Se trata de un pasadizo que conectaba los recintos IV y VI con el Recinto III (nótese el sello). Posteriormente se abre un acceso al lado Sur, en el segundo sub periodo A, como puede verse a la izquierda de la fotografía, que lo conectaba con el recinto $X$ (Recinto de los frisos). 


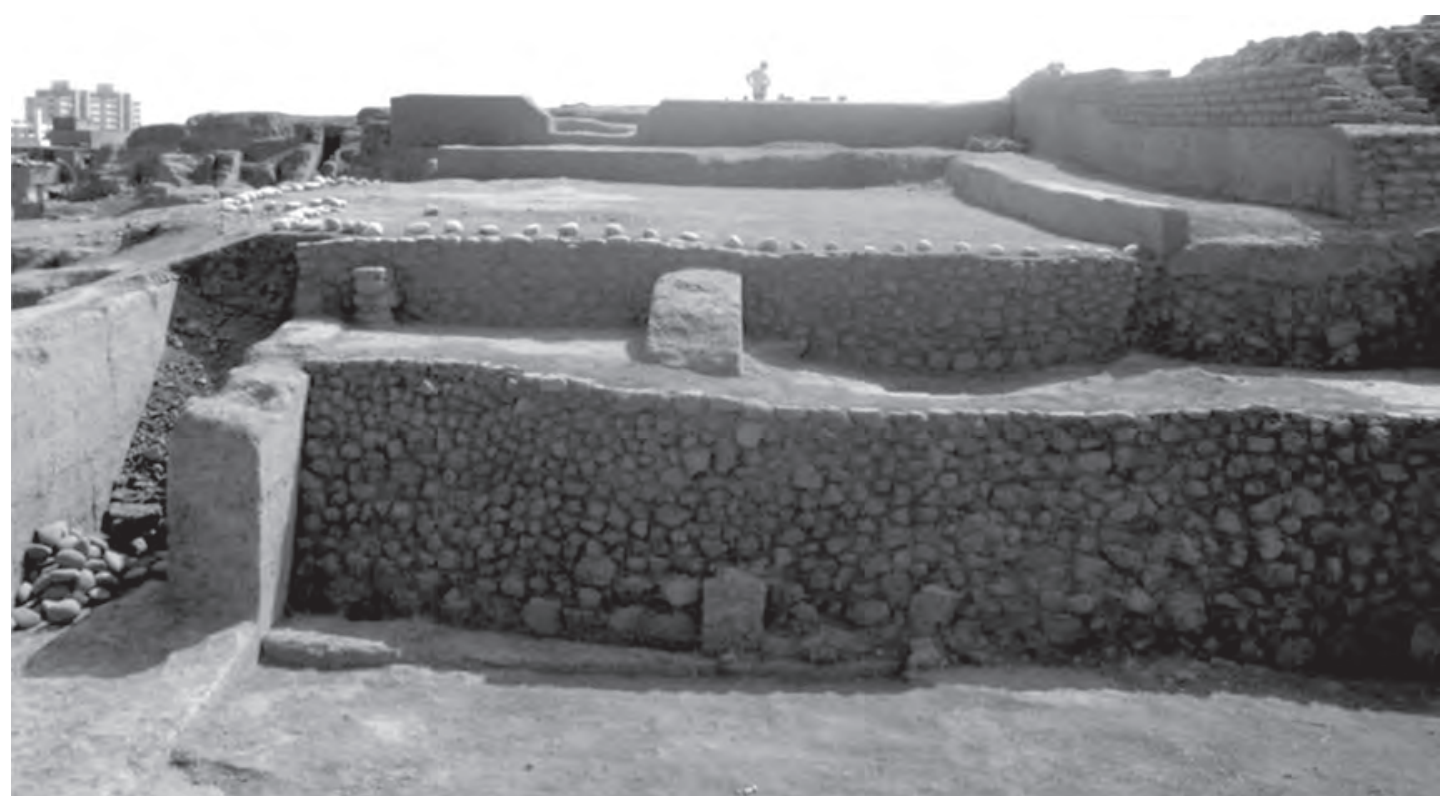

Figura 17. Recinto III; perteneciente al primer sub periodo del Periodo A. Nótese que se cubre el recinto con tapiales rotos y se llega a un nivel intermedio, que denominado segundo sub periodo del Periodo A, con recintos aun no definidos, pero que aún siguen asociados el muro con frisos. Posteriormente, se cubren estos recintos y se emplazan los recintos con banquetas en $L$, en el Periodo B.

Es en este periodo donde se registra ornamentación arquitectónica como la que se representa para el Recinto X, en un gran muro de $20 \mathrm{~m}$ de largo y 2,60 m de alto, cuya decoración es a través de frisos de representación geométrica y zoomorfa, el mismo que describiremos posteriormente, así como grafitis que representan aves marinas.

\section{CONTEXTOS ESPECIALES DE INVESTIGACIÓN PARA EL APORTE DE LA CARACTERIZACIÓN DE LA SOCIEDAD YCHSMA}

A continuación queremos describir de manera somera, cinco contextos que estimamos pueden aportar en el entendimiento del monumento Huantille: El hallazgo del muro con friso en el Recinto X; El sistema para rellenos constructivos denominado emparrillado, utilizado con una variante en el cubrimiento del Recinto 1 A; Los hoyos de ofrenda del Recinto I A; Las actividades en el enterramiento de las estructuras del Recinto $\mathrm{V}$ y el área de entierros.

\section{Hallazgo de muro con friso en el Recinto X}

El muro con friso fue hallado en dos cateos realizados el Recinto X, el mismo que encontramos cubierto, toda vez que perteneció al primer momento del Periodo B. El muro con friso fue denominado UE 161, de acuerdo a nuestro método de excavación, colinda al oeste con el Recinto III.(Ver fig.07, plano general)

Se trata de un Muro de tapia que corre en eje $\mathrm{N}$ - S, constituyéndose en el muro oeste de un corredor amplio denominado R X. ( Fig. 18)

El muro, está compuesta de dos paños, de apariencia firme pero con evidencia de deterioro en el paramento externo y destrucción en la parte superior. Esta estructura tiene un espesor de $80 \mathrm{~cm}$. La altura final es difícil de precisar debido al proceso de destrucción del que ha sido objeto, sin embargo 
la altura actual es de 2,60 m, se le asocia con el muro que conforma el límite sur del recinto III con el cual no llega a adosarse pero forma un acceso en la esquina SE del recinto. Este muro es bastante largo, llegando a los $20 \mathrm{~m}$, abarcando incluso la totalidad del recinto VIII. Lo más destacable del muro es la presencia de frisos en el paramento este; el diseño decorativo tiene una combinación de aves y un elemento escalonado hacia el Norte; el ave del diseño es un animal de pico alargado y curvo hacia abajo, cabeza redonda ojos redondos, cuello largo y ondulante y cuerpo redondeado rematado por una cola trapezoidal, este diseño se enmarca dentro de paneles cuadrados y se repite sucesivamente de manera horizontal; mientras que el diseño escalonado dentro de paneles va intercalándose con las aves de forma vertical: El friso ha sido elaborado en alto relieve, utilizando el barro como material de construcción, posteriormente se le aplicó una capa de pintura blanca sobre el diseño, mientras que el fondo aparece sin pintura, pero es posible que haya desaparecido. Al momento de clausurar este espacio se cubrió los motivos con una capa muy delgada de barro diluido formando una película protectora del friso (Fig. 19).

\section{Sistema de relleno constructivo del Recinto IA}

En el cubrimiento de los Recinto IA y Recinto IV, encontramos la técnica comúnmente llamada emparrillado. En el caso del Recinto IV este sistema se hizo a través de cantos rodados dispuestos a manera celdas y en el caso del Recinto I A, se utilizo una variante, a través de la disposición de hileras de tapial. Técnica que detallaremos a continuación, en base a la información obtenida de los siguientes Unidades Estratigráficas: 230, 231, 232, 233, 234, 235, 236, 237, 238, 239, 240, 241, cada una de ellas identificada con una hilera a manera de un muro estructural.

Las Unidades estratigráficas señaladas se tratan de un conjunto de grandes fragmentos de tapial apilados uno sobre otro y dispuestos a manera de hileras separadas una de otra en una distancia de $0,44 \mathrm{~m}$. Se orienta en línea oblicua al eje del recinto IA (orientación NW-SE).

Dichos alineamientos de carácter estructural conforman el relleno del Recinto IA. La composición de las hileras es de fragmentos de tapial rotos, en tamaños de 0,35 $\mathrm{m}$ a 0,50 m. Cada una de las hileras, se presentan a manera de una línea recta e irregular conformada varios fragmentos de tapial. El largo promedio es de 2,10 y 2,40 m, su altura máxima es de 1,76 m. (Fig. 20 y Fig. 21)

La técnica del emparrillado, como la variante descrita, al parecer conformaría una de las técnicas usuales de relleno constructivo, durante el periodo Intermedio Tardío para el valle del Rímac.

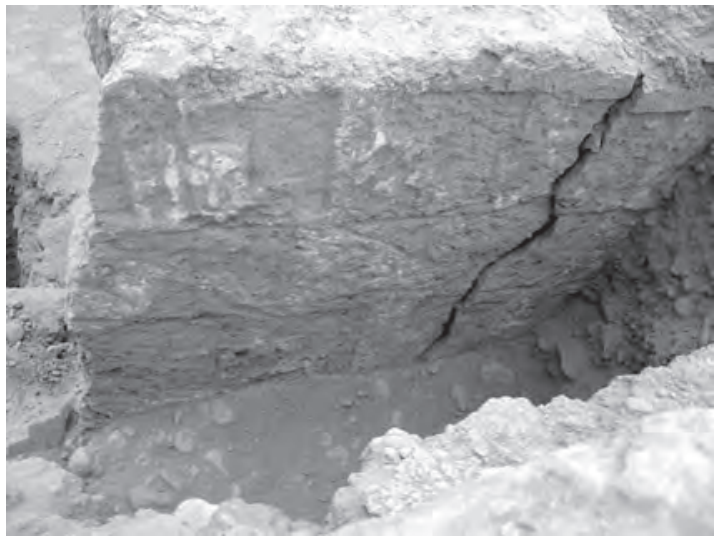

Figura 18. Los diseños se intercalan en los niveles, escalonado y ave, hasta abarcar la totalidad del muro, tanto en el largo, como en el alto.

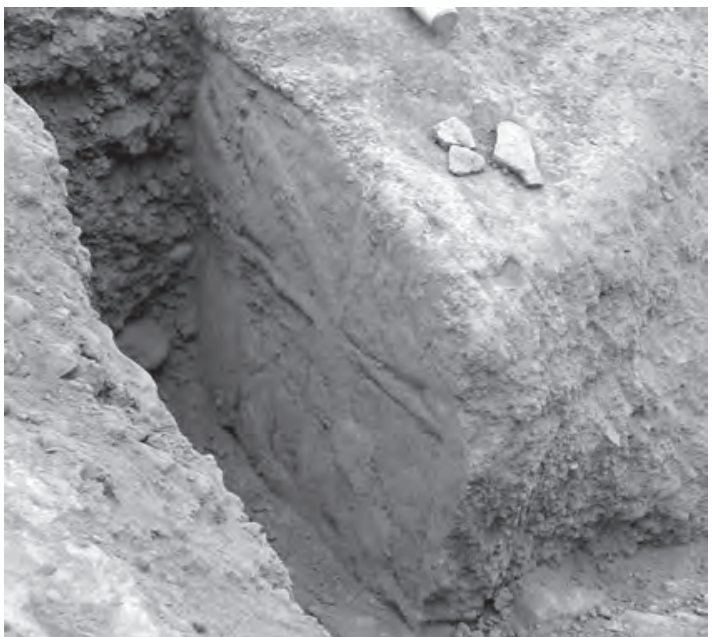

Figura 19. Capa de barro protectora sobre los relieves. 


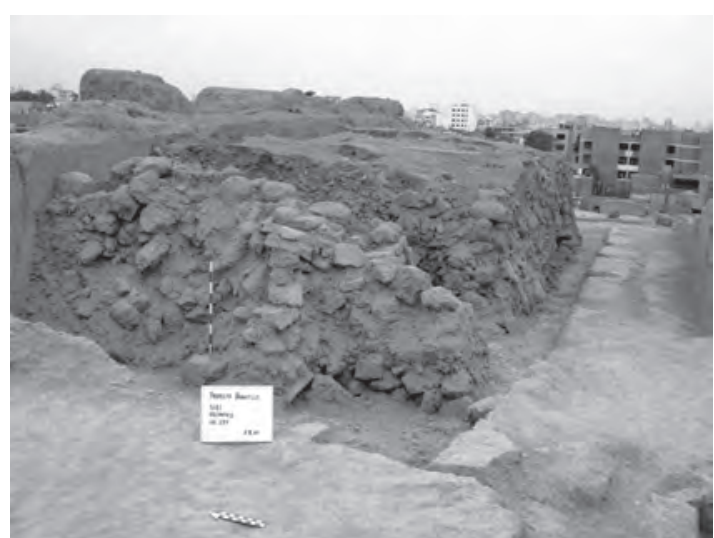

Figura 20. Vista del relleno constructivo en base a tapiales rotos que cubrían al Recinto $1 \mathrm{~A}$.

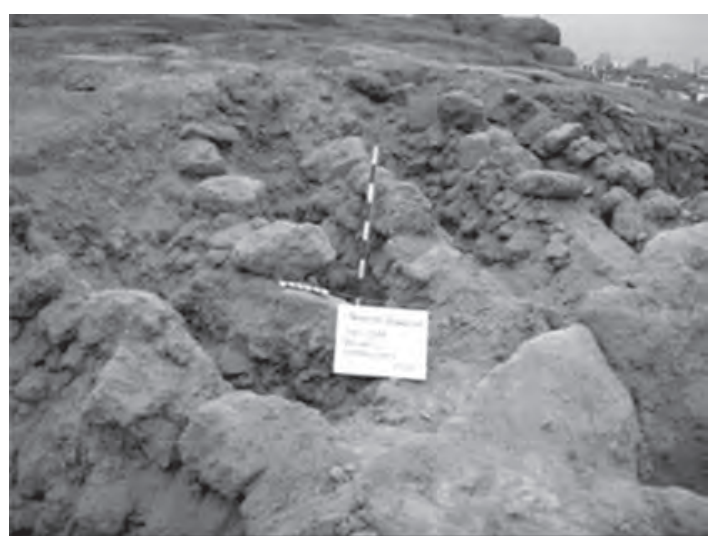

Figura 21. Vista en detalle del relleno constructivo en base a tapiales rotos, dispuestos a manera de hileras, que cubrían al Recinto 1 A. Una variante del típico "emparrillado".

\section{Los hoyos de ofrenda del Recinto I A}

Cortando el piso y los sobrepisos del Recinto I A se hallaron numerosos hoyos pequeños, de plata circular, de muy poca profundidad, que contenían ofrendas consistentes en restos vegetales, vertebras de pescado, cangrejos y en un caso un cuy (Fig. 22). A continuación, describimos los cortes más representativos de este tipo. Debemos señalar como mención aparte cuatro grandes hoyos al Este del Recinto que al parecer pudieron servir como base para tinajas. (Fig. 23).

\section{UE 247 (Corte)}

Este hoyo se localiza al Oeste de una línea de hoyos, que estuvieron conformados a su vez por la UE 248 y UE 249. La forma del corte es ovalada y presenta esquinas ligeramente redondeadas. Sus di-

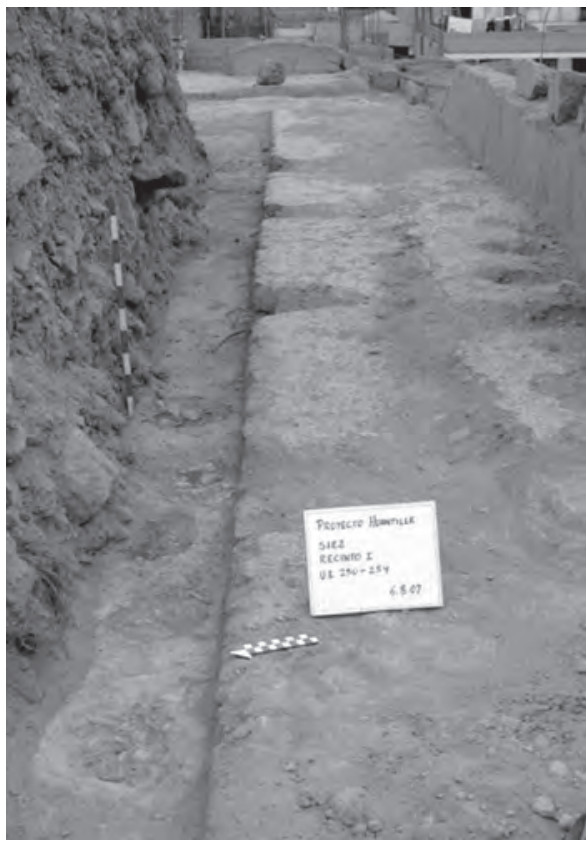

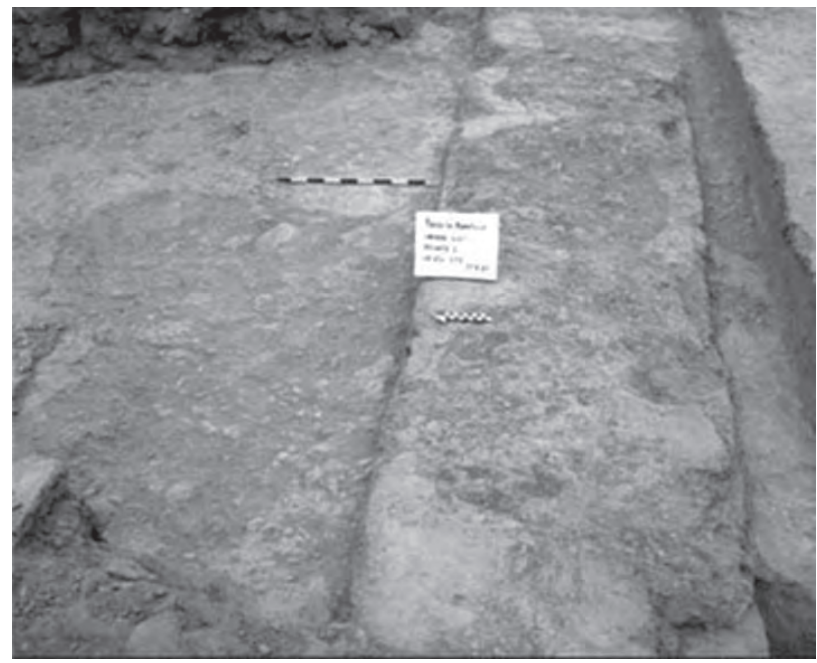

Figura 23. Vista de los grandes hoyos o roturas circulares sobre los pisos del Recinto I A.

Figura 22. Vista de los Hoyos UE 250 a 254 en el piso UE 263. 
mensiones son: 0,40 $\mathrm{m}$ de largo, 0,37 $\mathrm{m}$ de ancho y 0,31 $\mathrm{m}$ de profundidad. En su interior se hallaron, algunos restos de vértebras depescado, cangrejo, corontas de maíz y pequeños restos de carbón.

\section{UE 248 (Corte)}

Este hoyo se localiza al centro de la línea de los hoyos precitada. Sus dimensiones son: 0,38 m de largo, $0,38 \mathrm{~m}$ de ancho y $0,27 \mathrm{~m}$ de profundidad. El corte se orienta en dirección NE-SW. En su interior se hallaron restos de cangrejo.

\section{UE 249 (Corte)}

Al interior de este hoyo se encontraron restos de cangrejo y vértebras de pescado, carrizo y corontas de maíz.

\section{UE 250 (Corte)}

Se ubica en el piso más bajo del recinto IA, al Este de una línea de hoyos que bordean el sobre piso del lado sur y que estuvo conformada además por las UE 251, UE 252, UE 253, UE 254. Sus dimensiones son: 0,39 $\mathrm{m}$ de largo, 0,34 $\mathrm{m}$ de ancho y 0,33 $\mathrm{m}$ de profundidad. En su interior se registraron, restos de caña, corontas de maíz, plumas pequeñas, restos de un roedor pequeño, cáscara de maní y algunos fragmentos de cangrejo.

\section{UE 251 (Corte)}

Sus dimensiones son: 0,30 $\mathrm{m}$ de largo, 0,30 $\mathrm{m}$ de ancho y 0,15 $\mathrm{m}$ de profundidad. En su interior se registraron, restos de caña (carrizo) distribuidas al azar, cáscara de maní, restos de vértebra de pescado y algunos fragmentos de cangrejo.

\section{UE 252 (Corte)}

La forma del corte es semicircular y presenta esquinas redondeadas. Sus dimensiones son: $0,31 \mathrm{~m}$ de largo, 0,35 $\mathrm{m}$ de ancho y 0,15 $\mathrm{m}$ de profundidad. En su interior, se hallaron restos de caña (carrizo) distribuidas al azar y corontas de maíz.

\section{UE 253 (Corte)}

Sus dimensiones son: 0,33 $\mathrm{m}$ de largo, 0,32 $\mathrm{m}$ de ancho y 0,18 $\mathrm{m}$ de profundidad. En su interior, se hallaron restos de caña, corontas de maíz y fragmentos de cangrejo. El hoyo corta a la UE 263, que es el piso más bajo del recinto IA.

\section{UE 254 (Corte)}

Sus dimensiones son: 0,34 $\mathrm{m}$ de largo, 0,27 $\mathrm{m}$ de ancho y 0,04 $\mathrm{m}$ de profundidad. Presentó en su interior algunos pocos restos de caña, y algunos fragmentos de choros. El hoyo corta a la UE 263, que es el piso más bajo del recinto IA. El relleno que contuvo se conformó de los materiales de la UE 224.

\section{UE 255 (Corte)}

Se trata de una gran rotura de forma circular ubicada en el piso elevado del recinto IA, la UE 266 (Fig. 23). Posiblemente es un corte provocado por la presencia de una gran vasija de almacenamiento. Esta rotura se ubica al Este de otras dos roturas similares que abarcan casi toda el área de la UE 266 al borde del límite occidental del recinto. La forma del corte es circular y presenta esquinas redondeadas. Sus 
dimensiones son 1,16 $\mathrm{m}$ de largo, 1,20 $\mathrm{m}$ de ancho y 0,46 $\mathrm{m}$ de profundidad. La forma de la rotura es aguda en la parte superior, es decir casi recta; y sus lados descienden en forma vertical paralela. Su base está definida por dos estructuras (un muro y un piso) que corresponden a una fase precedente a la conformación del recinto IA. Presentó en su interior algunos fragmentos de cerámica, fragmentos de cangrejo y algunos restos de ceniza concentrada principalmente a los lados. El hoyo corta la UE 266 , que es el piso elevado del recinto IA.

\section{Actividades en el enterramiento del Recinto $\mathrm{V}$}

El Recinto V, es un espacio ubicado al Este del Edificio, que fue enterrado para la construcción de las plataformas del Periodo $\mathrm{C}$.

Es una plataforma rectangular de aproximadamente $4 \mathrm{~m}$ de ancho por $15 \mathrm{~m}$ de largo, remanente de un espacio mucho más amplio que se extendía hacia el Norte, Sur y Este. Hacia el Sur de este recinto se observan los restos de una escalera de 4 pasos (Fig. 24).

Sobre el piso de la plataforma se identificó una densa capa de material orgánico, principalmente vegetal, que se presenta compactado y con algunos fragmentos de moluscos y cangrejos, en algunos sectores se observan apelmazado y unidos con barro y piedras pequeñas de cantos rodados, así como hoyos irregulares conteniendo diversos productos (Fig. 25). Este evento estaría asociado a la práctica de banquetes rituales o a una gran ceremonia de abandono de este espacio antes y durante la colocación del relleno constructivo, dado que en los rellenos se hallo carbón de restos de vegetales y quemas. Asimismo, para su enterramiento se utilizaron bloques de tapial que conformaron el muro con frisos (Fig. 26).

\section{Área de entierros}

Se ha identificado dos momentos en los entierros hallados en el área mortuoria de la Huaca Huantille, la cual se ubica en su esquina Sur Oeste.(Fig. 27)

Un primer momento de época Ychsma con los individuos dispuestos en posición fetal, circunscritos en cañas, comparable con lo identificado para Armatambo por la Lic. Luisa Díaz; así como circunscritos en cistas de adobe o cantos rodados, a manera de pequeños cuartos o celdas rectangulares de 1,5 x 1,5 m; algunos están acompañados con objetos de metal (pinzas) encontradas en el tórax y otros acompañados de vasijas, hacia los lados del individuo. La mayoría de los individuos estaban asentados sobre grandes mates. Un detalle peculiar es la identificación de un infante de menos de 02 años de edad con deformación braquiocefálica.

El segundo momento de enterramientos, vino al parecer al momento de la reducción española, por la cual los individuos se extienden de manera horizontal, con tela llana y sin mayores asociaciones. Este segundo momento, se halla exactamente encima de los primeros entierros.

El patrón funerario y sus especificaciones aun están en proceso de investigación, y serán motivo para una siguiente publicación; sin embargo queríamos mostrar este pequeño adelanto de la información para discusión de los investigadores.

\section{CONCLUSIONES}

Huaca Huantille se constituyó en un centro importante de la sociedad Ychsma, más precisamente del curacazgo de Lima, con una extensión similar al de Mateo Salado; quedando solo, de su edificio más importante, el 30\% de su extensión original( 3 ha.) y de sus otros cuatro monumentos que lo circundaban, no queda nada en la actualidad, por la ampliación urbana.

Las excavaciones han permitido definir, en cuanto a la arquitectura del monumento, estar frente a un pirámide con una gran escalinata de acceso principal, la cual diversifica las formas arquitectónicas del intermedio Tardío en el valle del Rímac, más allá de la pirámide con rampa típica; además en la 


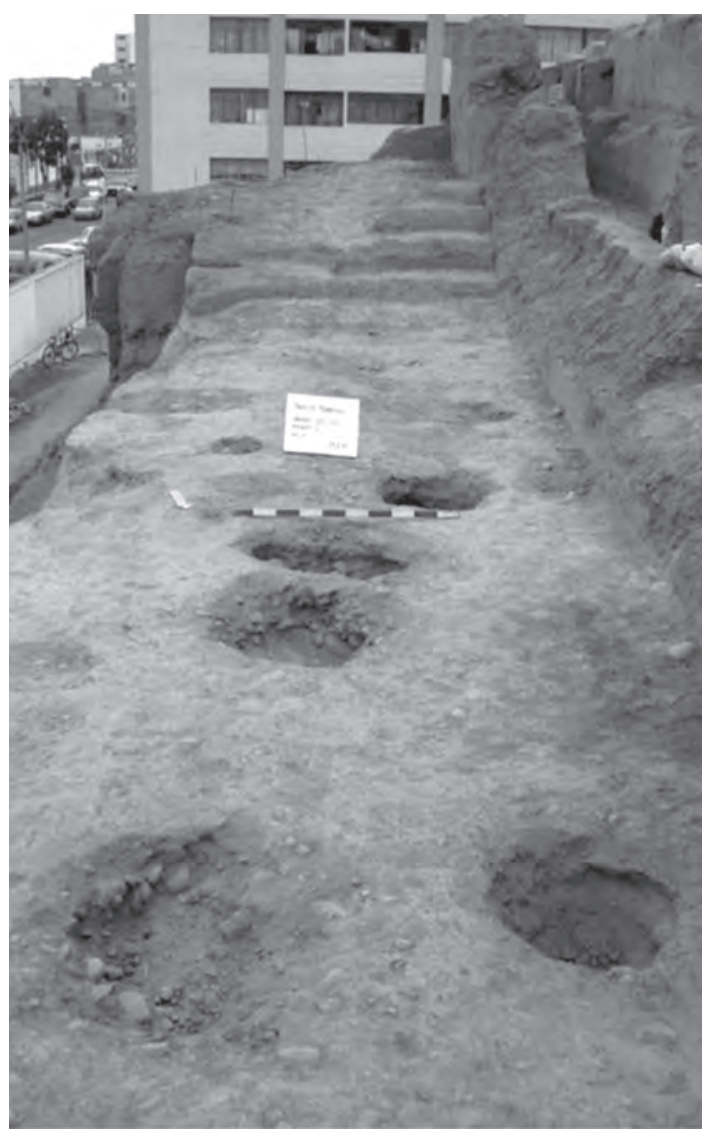

Figura 24. Plataforma con apelmazado de vegetales y hoyos de ofrendas. Nótese las escaleras hacia el fondo.

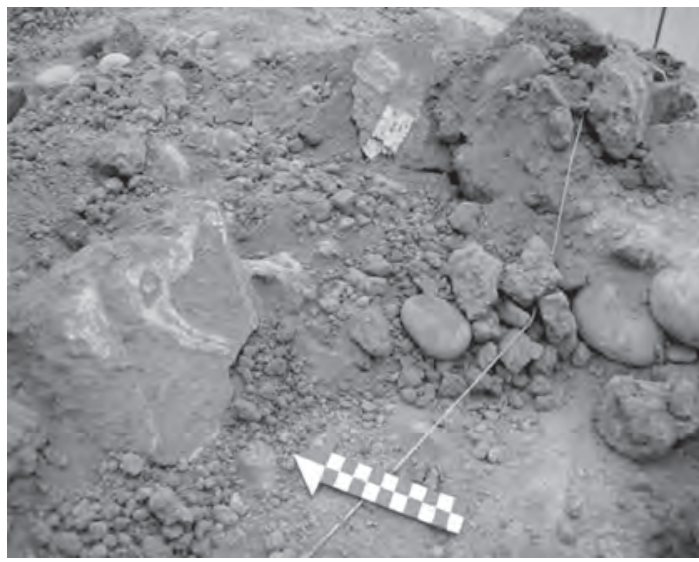

Figura 26. Detalle de fragmentos del friso utilizados para el enteramiento del Recinto $V$.

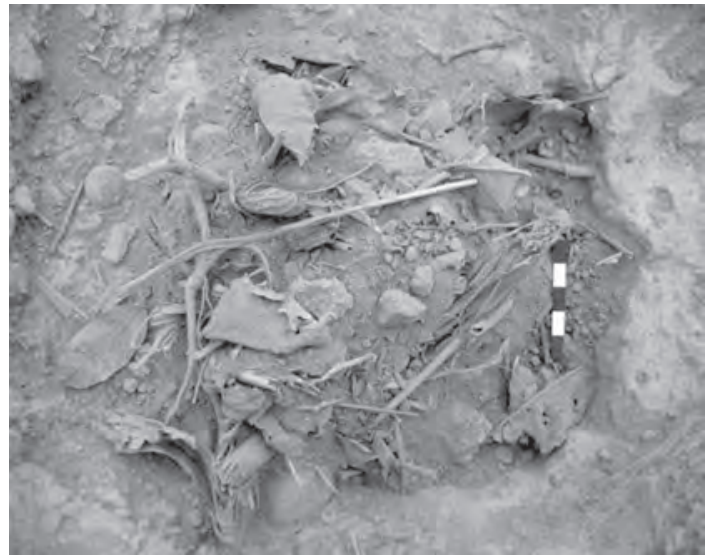

Figura 25. Ofrenda de vegetales recuperada en uno de los hoyos mostrado líneas arriba.

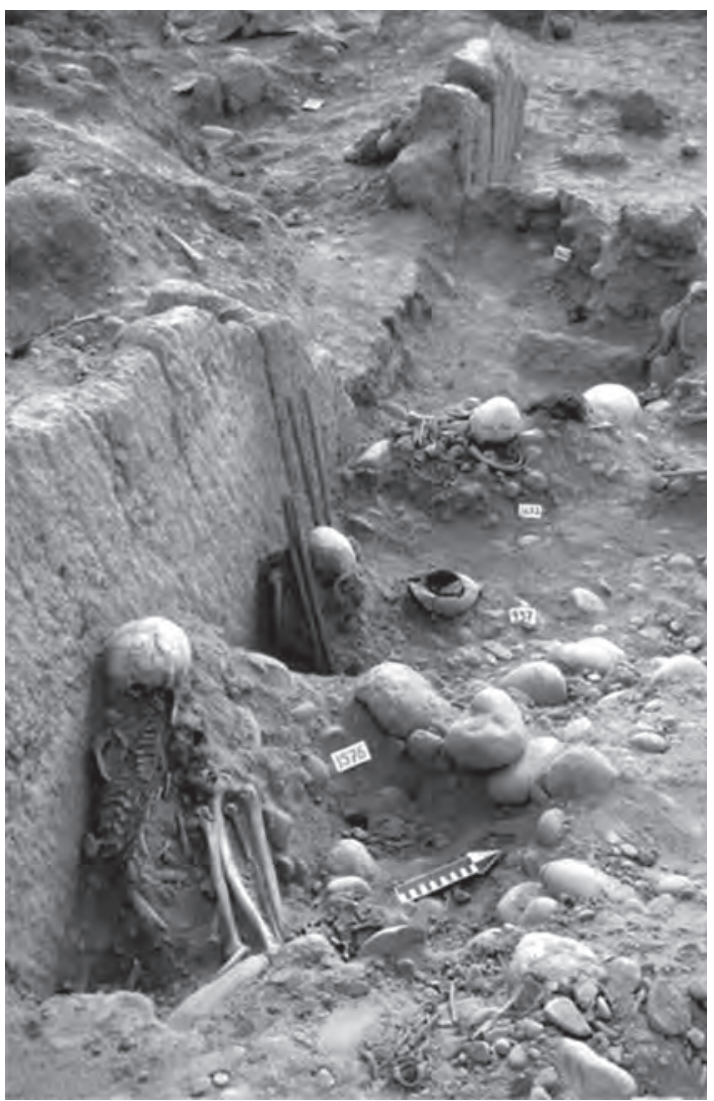

Figura 27. Individuos en posición fetal.

cima hay presencia de recintos caracterizados por ser de planta rectangular, con muros de tapial bien acabados y pintados de blanco en su gran mayoría, así como pisos de buena factura. 


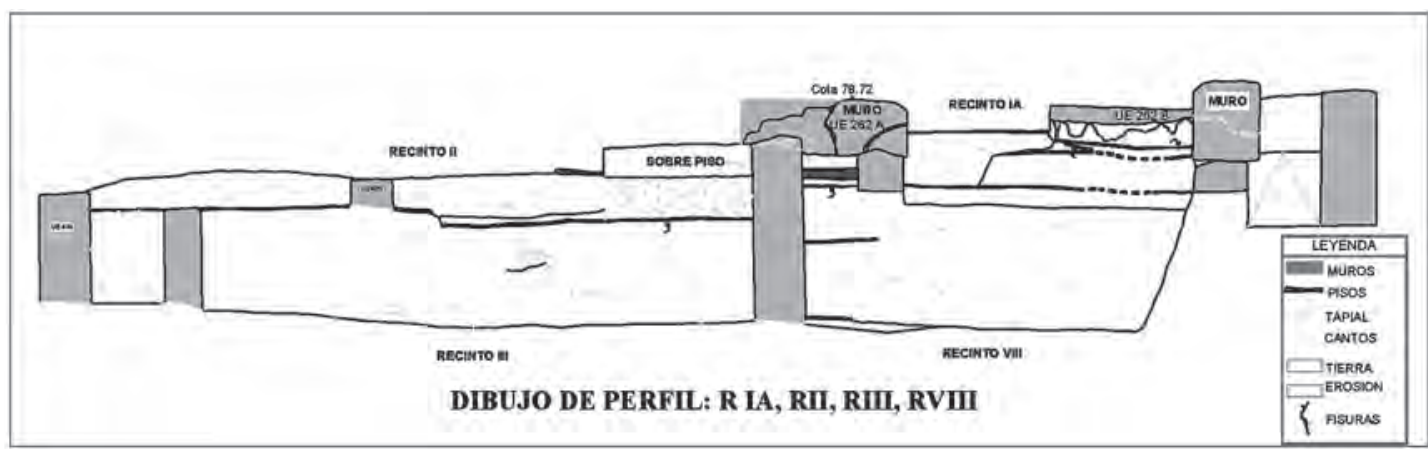

Figura 28. Dibujo de perfil: R I A, R II, RVIII.

Se ha determinado tres periodos de ocupación de manera clara tras las excavaciones, no descartándose encontrar, en el futuro con las excavaciones, hasta un periodo inferior, aun no determinado.

El periodo $\mathrm{B}$ y $\mathrm{C}$, se halla claramente definido por los espacios con sobre pisos en L, mientras que en el Periodo A, no se halla ninguno en el registro. Asimismo, no hay gran cambio en la orientación de la arquitectura que está definida entre $20^{\circ}$ y $21^{\circ} \mathrm{E}$ con respecto al norte

Los recintos con pisos a desnivel en forma de L, tendrían carácter ceremonial, así como se ha podido definir habitaciones como es el caso del Recinto XII, R XIV y R XVI. Los accesos se realizaban a través de vanos a nivel del piso, escalinatas, escaleras y pasadizos.

El material arqueológico preponderante es fragmentería de cerámica Ychsma caracterizada por cántaros grandes y medianos, tinajas y vasijas utilitarias, ollas por lo general; así como pequeñas jarras para el vertido de líquido. También se identificaron fragmentos de figurinas, tanto antropomorfas como zoomorfas. Asimismo se observan varios fragmentos de cerámica Chancay, por lo general identificados con cantaros medianos, muchos de ellos importados (Figs. 30-36).

Los eventos de demolición y construcción mediante rellenos estaban precedidos por ceremonias en las cuales se ofrendaban vegetales, tales como hojas de pacae, frutos y cáscaras de maní, cañas y tuzas de maíz entre los más significativos.

En algunos rellenos se ha observado también grandes concentraciones de grama salada. Estas ofrendas se colocaban sobre superficies húmedas y en algunos casos en medio de los rellenos como en el Recinto V o sobre los pisos como ocurre para los Recintos XIII y XIV.

A veces las ofrendas consisten en productos marinos tales como cangrejos y/o peces en cuyo caso se colocan en pequeños hoyos superficiales, no siendo raro hallarlos junto con maní y hojas de pacae. Otro tipo de ofrendas consiste en la rotura de grandes tinajas y cántaros, y aparecen ya sea sobre los pisos o a poca distancia de ellos en los rellenos.

La cerámica analizada nos muestra que Huantille tenía algún tipo de acceso a material importado, mediante redes de intercambio, de ahí la presencia significativa de cerámica Chancay en los rellenos y textiles de influencia norteña y de la costa sur que acompañaban a los entierros de individuos.

La presencia Inca en Huantille, no está bien definida, quizás por el grado de destrucción de su último periodo de ocupación o porque aun faltan ampliar mas las excavaciones.

\section{Agradecimientos}

Agradecer a mi madre por apoyarme incondicionalmente en mi carrera, a Pieter Van Dalen que me permite, a través de la presente publicación, mostrar a la sociedad las investigaciones del Proyecto Huantille, a Luis Flores Blanco por su impulso para escribir el presente artículo, a Rafael Moreno Mezarina por la edición de los planos del Proyecto, al equipo de trabajo del año 2007-2008 y 2011. 


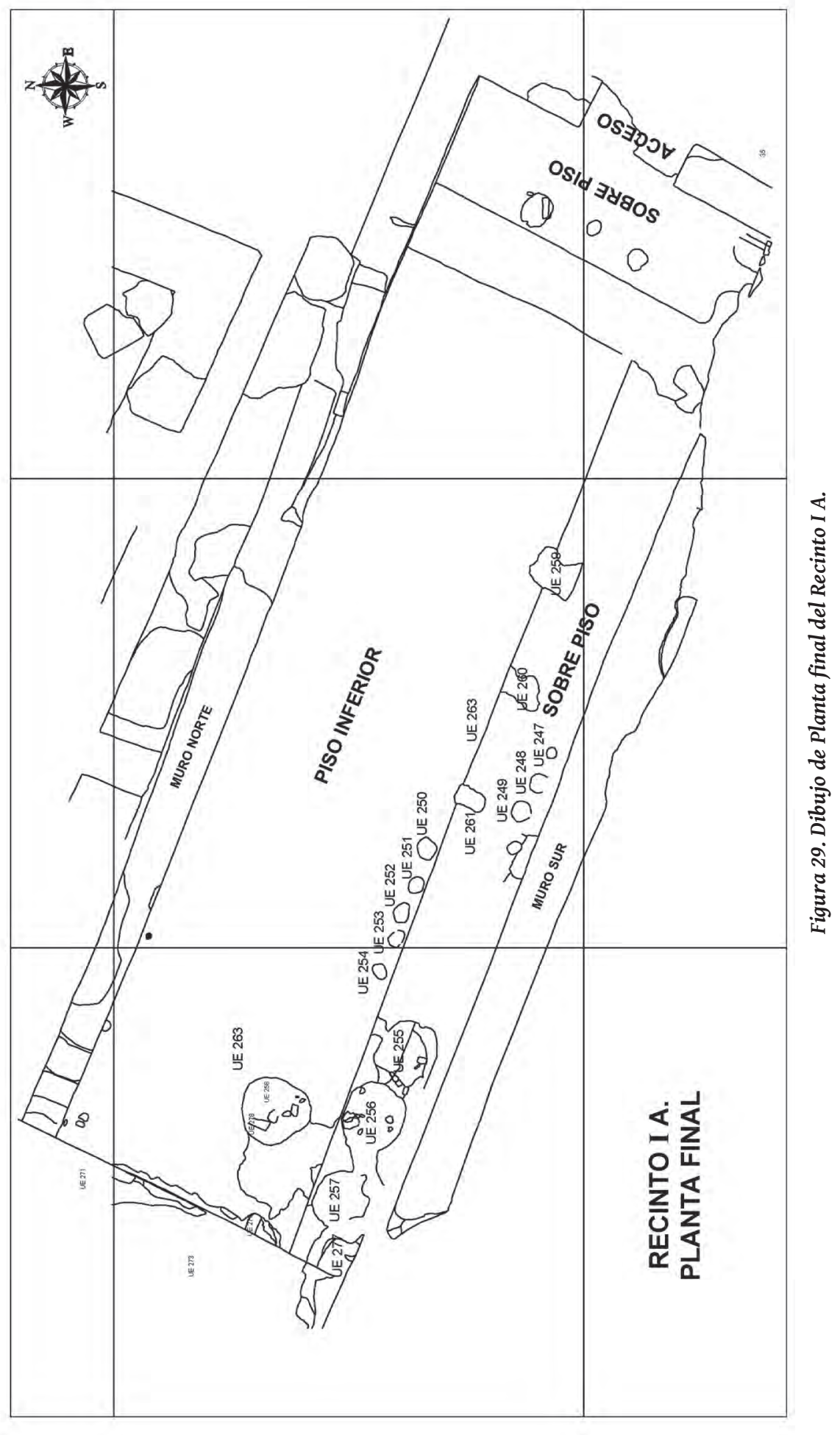




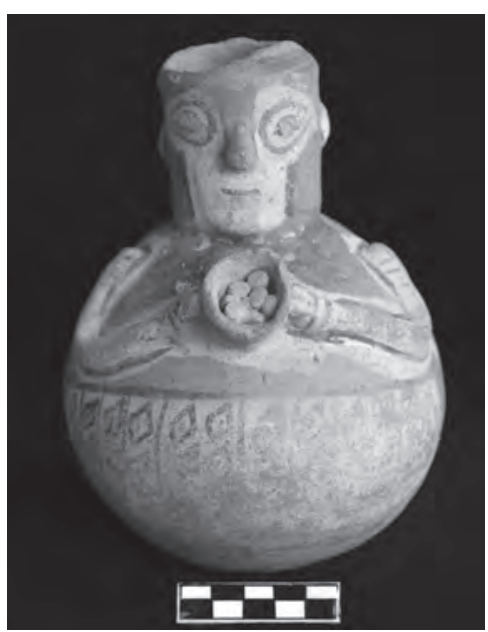

Figura 34. Botella escultórica.

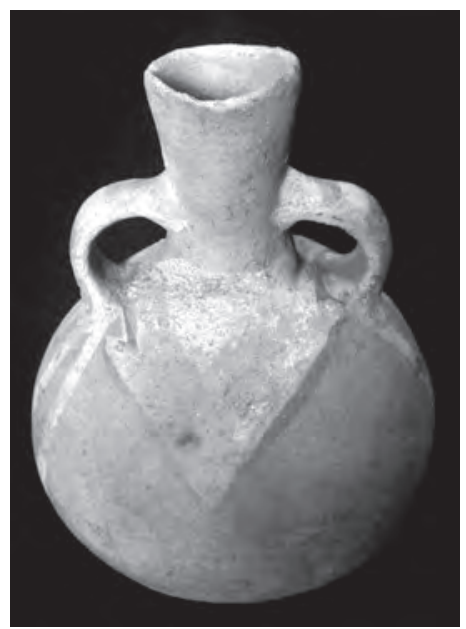

Figura 35. Botella Ychsma.

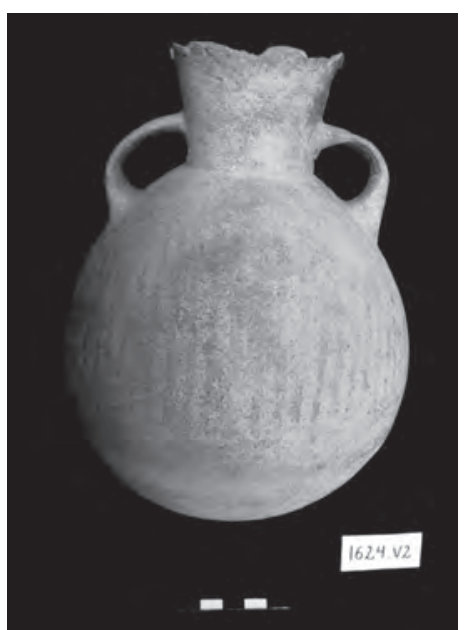

Figura 36. Botella Chancay.

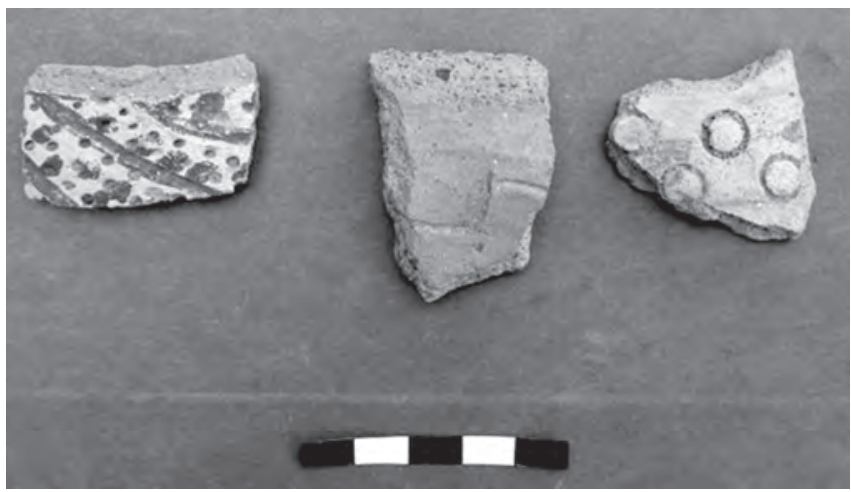

Figura 30. Fragmentería Yschma.

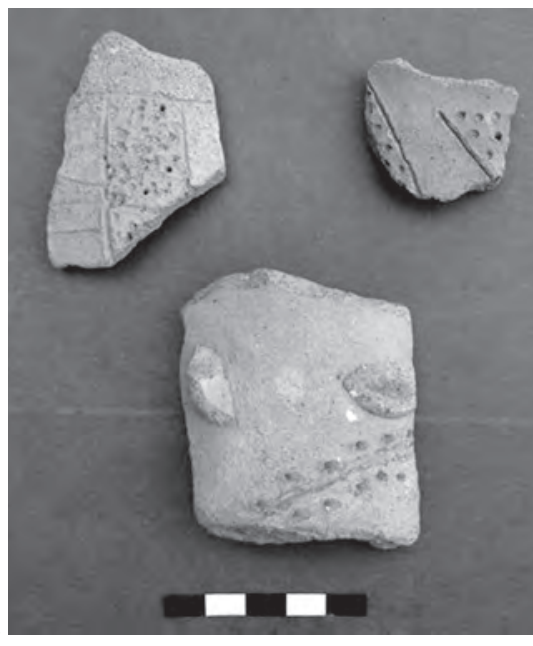

Figura 31. Fragmentería Yschma.

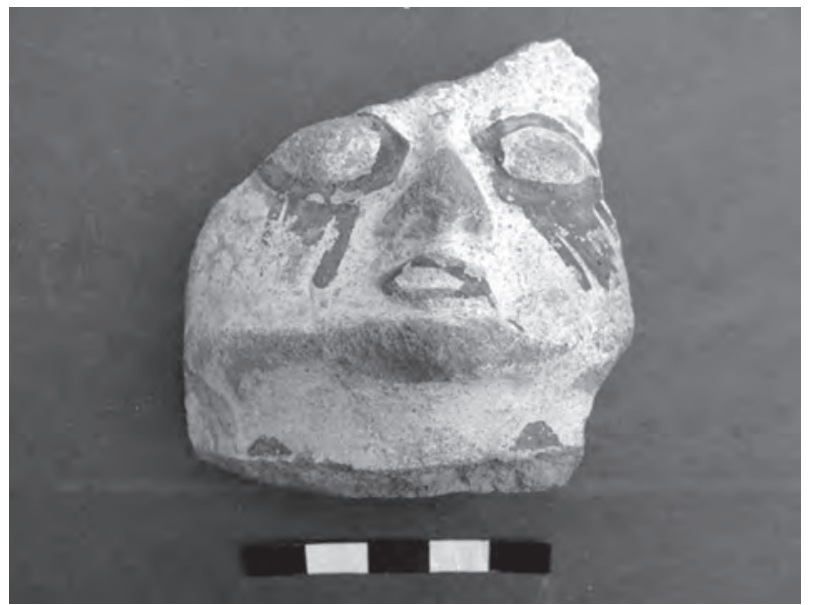

Figura 32. Fragmentería Chancay.

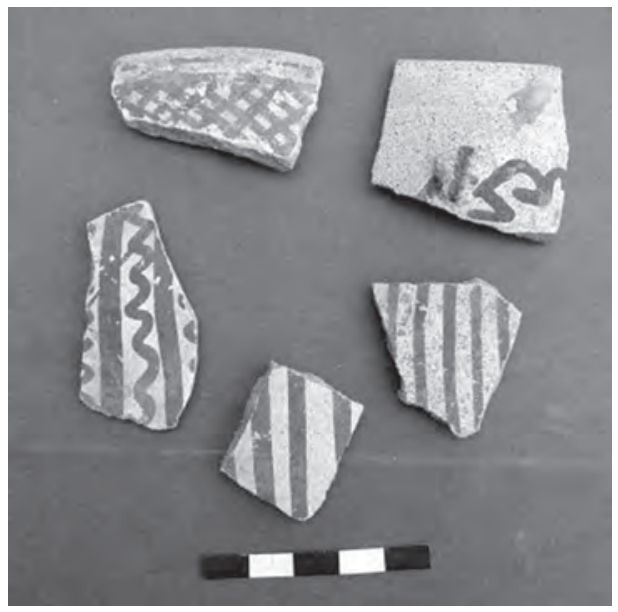

Figura 33. Fragmentería Chancay. 


\section{BiBLIOGRAFÍA}

AGURTO CALVO, Santiago

1984 Lima Prehispánica. Municipalidad de Lima Metropolitana Edit. pp. 122-123

BALLART, J.

1997 "El patrimonio Histórico y Arqueológico: valor y uso". Barcelona: Editorial Ariel. Valencia, A., and A. Gibaja. 1992. Machu Pichu: La Investigación y Conservación de los Monumentos Arqueológicos después de Hiram Bingham. Cusco, Perú.

CEDILLO ALVAREZ, Luciano

1993 "Estuco: Informe de los métodos desarrollados en México". En: Conservación Arqueológica In Situ. (Henry W. M. Hodges, editor): 96 - 103. Memoria de las reuniones 6-13 de abril de 1986, México. Instituto Nacional de Antropología e Historia de México. Instituto Getty de Conservación.

DÍAZ ARRIOLA, Luisa

2004 “Armatambo y la Sociedad Ychsma”. Arqueología de la Costa Central del Perú en los Periodos Tardíos. Boletín del Instituto Francés de Estudios Andinos. Lima, Tomo 33, № 03. pp. 572-594

EECKOUT, Peter

2004 "La Sombra Ychsma. Ensayo Introductorio sobre la Arqueología de la Costa Central del Perú en los Periodos Tardíos". Arqueología de la Costa Central del Perú en los periodos tardíos. En: Boletín del Instituto Francés de Estudios Andinos. Lima, Tomo 33, № 03. pp. 408-411

GALVEZ, César, Antonio MURGA, Denis VARGAS y Hugo RIOS

2003 "Secuencia y cambios en los materiales y técnicas constructivas de la Huaca Cao Viejo, Complejo El Brujo". En: Moche: hacia el final del milenio. T. I (S. Uceda y E. Mujica, eds.): 79 - 118. Actas del Segundo Coloquio sobre la Cultura Moche (Trujillo, 1 al 7 de agosto de 1999). Universidad Nacional de Trujillo y Pontificia Universidad Católica del Perú, Lima.

\section{KAKOULLI, Ioanna}

1997 Materials and Techniques of the pre-Hispanic Paintings at El Brujo,HuacaCao Viejo, Peru. Research Laboratory for Archaeology and the History of Art. Universidad de Oxford, Oxford.

MEUCCI, Constantino

1993 Análisis de Relieves de la Huaca Cao. Informe preliminar presentado a la Fundación Augusto N. Wiese (Manuscrito).

MORALES, Ricardo

1994 “La conservación de relieves de barro policromos en la costa norte del Perú". En: Moche. Propuestas y Perspectivas. Santiago Uceda y Elías Mujica, editores. Actas delPrimer Coloquio Sobre la Cultura Moche -1993. Travaux de L'Institud Francais D’Etudes Andines, pp. 477-492, Lima.

RAVINES, Roger

1984 Inventario de Monumentos Arqueológicos del Perú - Lima Metropolitana. INC/ Municipalidad de Lima Metropolitana. Lima.

ROSTWOROWSKY de DIEZ CANSECO, María

1978 Señoríos de Lima y Canta. Historia Andina 7, Instituto de Estudios Peruanos, Lima.

STUMER, Louis M.

1954 "Historia de las Ciudades del Valle del Rímac". Revista del Museo Nacional 23: 212-239. Lima.

TELLO ROJAS, Julio C.

1999 Arqueología del Valle de Lima. Cuadernos de Investigación del Archivo Tello. Museo de Arqueología y Antropología de la UNMSM. 138 p. 